
LEGAL NOTICE.

This report was prepared as an account of Government sponsored work. Neither the United States, nor the Commission, nor any person acting on behalf of the Commission:

A. Makes any warranty or representation, expressed or implied, with respect to the accuracy, completeness, or usefulness of the information contained in this report, or that the use of any information, apparatus, method, or process disclosed in this report may not infringe privately owned rights; or

B. Assumes any liabilities with respect to the use of, or for damages resulting from the use of any information, apparatus, method, or process disclosed in this report.

As used in the above, "person acting on behalf of the Commission" includes any employe or contractor of the Commission, or employe of such contractor, to the extent that such employe or contractor of the Commission, or employe of such contractor prepares, disseminates, or provides access to, any information pursuant to his employment or contract with the Commission, or his employment with such contractor. 


\section{DISCLAIMER}

This report was prepared as an account of work sponsored by an agency of the United States Government. Neither the United States Government nor any agency Thereof, nor any of their employees, makes any warranty, express or implied, or assumes any legal liability or responsibility for the accuracy, completeness, or usefulness of any information, apparatus, product, or process disclosed, or represents that its use would not infringe privately owned rights. Reference herein to any specific commercial product, process, or service by trade name, trademark, manufacturer, or otherwise does not necessarily constitute or imply its endorsement, recommendation, or favoring by the United States Government or any agency thereof. The views and opinions of authors expressed herein do not necessarily state or reflect those of the United States Government or any agency thereof. 


\section{DISCLAIMER}

Portions of this document may be illegible in electronic image products. Images are produced from the best available original document. 


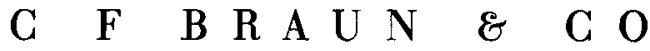 \\ Engineers}

A L HAM B RA CALIFORNIA 918002

\section{SAN.781.240}

February 13, 1969

Mr H B Fry

Contracting Officer, Contract AT(04-3)-781

AEC San Francisco

2111 Bancroft Way

Berkeley, California 94704 BAL -30

Dear Mr Fry

INSTABILITY ANALYSIS METHODS

TECHNICAL REPORT 240

LMFBR PIPING DESIGN GUIDE

PROJECT 4122-W

Transmitted herewith are two copies of the draft report covering studies of Instability Analysis Methods as related to LMFBR piping systems.

The purpose of the study was to review existing methods of instability analysis to select suitable procedures for incorporation into the design guide.

An eight-week period is allowed for review and return of comments to Braun. Comments should be mailed by April 10 to

C F Braun \& Co

Dr R F Detman, Project Manager

Alhambra, California 91802

RFD IV

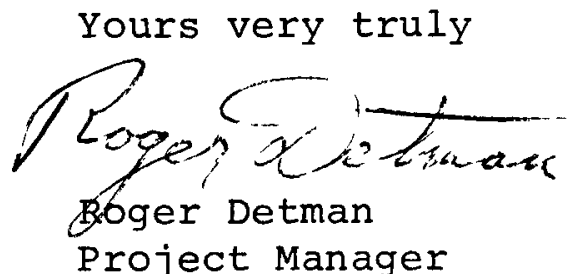

This report LEAL NOTICE

sponsored by the Unepared as an account of work

the United States nor the States Government. Neither

Commission, ntes nor the United States Atomic Ener

their contractors, any of their employees, nor any of

makes any warranty, expractors, or their employees,

legal liability or responsibility implied, or assumes any

pleteness or responsibility for the accuracy com

product or process disclosed information, apparatus,

would not infringe disclosed, or represents that its use

Project Manager

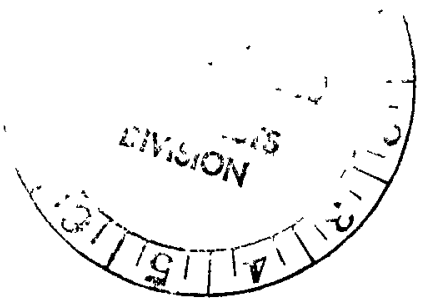




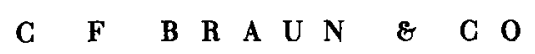

Project $4122-W$

Mr H B Fry

Page 2

AEC Contract AT (04-3)-781

February 13, 1969

CC H B Fry, Contracting officer -original and one Director, RDT, HQ

Asst. Director, Plant Engineering, RDT, HQ

RDT Senior Site Representative (AI) -2

Director, LMEC -8 


\title{
A STUDY OF INSTABILITY ANALYSIS METHODS
}

AS RELATED TO LMFBR PIPING SYSTEMS

TECHNICAL REPORT 240

\begin{abstract}
This report
sponsored by was prepared as an account of work sponsored by the United States Government. Neither the United States nor the United States Atomic Energy Commission, nor any of their employ Atomic Energy their contractors, subcontrair employees, nor any of makes any warrantroctors, or their employees, legal liability or egal liability or responsibility for the accuracy, any pleteness or usefulness of any inform product or process disclosed, information, apparatus, would not infringesents that its use would not infringe privately owned rights.
\end{abstract}

\author{
Prepared for US Atomic Energy Commission \\ Contract No AT (04-3) -781 \\ Braun Project $4122-\mathrm{W}$
}

United Nuclear Project 2351

\author{
UNITED NUCLEAR CORPORATION \\ Research and Engineering Center \\ Elmsford, New York
}

February 13, 1969 
TABLE OF CONTENTS

1. INTRODUCTION. . . . . . . . . . . . . . 1-1

2. GENERAL DISCUSSION ........... 2-1

2.1 Definition of Instability of Buckling . . . . . . 2-1

2.1.1 Elastic Buckling. . . . . . . . . . . 2-1

2.1.2 Inelastic Buckling . . . . . . . . . . . 2-1

2.1.3 Creep Buckling . . . . . . . . . . . . . 2-2

2.2 Conditions for Instability . . . . . . . . . . 2-2

2.3 Present Theory State-of-the-Art . . . . . . . 2-3

2.3.1 Elastic Instability . . . . . . . . . . 2-3

2.3.2 Inelastic Instability . . . . . . . . . 2-7

2.3.3 Creep Instability . . . . . . . . . . . . 2-7

2.4 Present State-of-the-Art of Experiments . . . . 2-7

2.4.1 Elastic Instability ........... 2-7

2.4.2 Inelastic Instability . . . . . . . . 2-8

2.4.3 Creep Instability . . . . . . . . . . . 2-8

3. REVIEW OF ANALYSIS METHODS AND EXPERI-

MENTAL DATA FOR STRAIGHT PIPE UNDER

VARIOUS LOADING CONDITIONS . . . . . . . . . 3-1

3.1 Cylinder under Axial Loading . . . . . . . . . . 3-1

3.1.1 Cylinder under Axial Compression Only . . . 3-1

3.1.2 Cylinder under Axial Compression

Including Internal Pressure . . . . . . . 3-10

3.1.3 Cylinder under Axial Compression

Including External Pressure . . . . . . 3-14

3.1.4 Cylinder under Axial Tension and

Combined with Internal Pressure . . . . . 3-14 
3. 2 Cylinder under Torsion .................. 3-14

3.2. 1 Cylinder under Torsion Only ............ 3-16

3.2.2 Cylinder under Torsion and External

Pressure - Elastic Buckling ........... 3-22

3. 3 Cylinder under Bending .................. 3-29

3. 3. 1 Cylinder under Bending Only ............ 3-29

3. 3. 2 Cylinder under Bending Including

Internal Pressure - Elastic Buckling ....... 3-31

3. 4 Cylinder under Internal Pressure ............. 3-31

3. 5 Cylinder under External Pressure ............ 3-35

3.5.1 Cylinder under Lateral External Pressure ... 3-35

4. ANALYSIS METHODS FOR ELBOWS, LATERALS,

TEE'S, LOCAL PADS FOR HANGERS, SUPPORTS, ETC . 4-1

4. 1 Analysis Methods for Elbows and Returns ......... 4-1

4. 2 Analysis Methods for Welded Tubular

Connections ......................... 4-6

4. 3 Analysis Methods for Local Pads for Hangers,

Supports, etc ..................... 4-7

5. REQUIRED DEVELOPMENT WORK ............. 5-1

6. COMPUTER PROGRAMS $\ldots \ldots \ldots \ldots \ldots \ldots \ldots \ldots \ldots, 6-1$

6. 1 Codes for Elastic Buckling ................. 6-1

6. 2 Codes for Inelastic Buckling ............... 6-5

6. 3 Codes for Creep Buckling $\ldots \ldots \ldots \ldots \ldots \ldots \ldots \ldots$ 6 6-6

7. RECOMMENDATIONS FOR INSTABILITY ANALYSIS

PROCEDURES ........................ $7-1$

7. 1 Instability in the Elastic Range $\ldots \ldots \ldots \ldots \ldots \ldots \ldots$ 7-1

7.1.1 Axial Compression ................. 7-2

7.1.2 Axial Compression Plus Internal Pressure ... 7-2

7.1.3 Axial Compression Plus External

Pressure .................... 7-2

7. 1.4 Torsion $\ldots \ldots \ldots \ldots \ldots \ldots \ldots \ldots \ldots \ldots \ldots, 7-2$

7. 1. 5 Torsion Plus External or Internal

Pressure ...................... 7-2

7.1 .6 Bending $\ldots \ldots \ldots \ldots \ldots \ldots \ldots \ldots \ldots \ldots \ldots, 7-3$

7. 1. 7 Bending Plus Internal Pressure ......... 7-3

7. 1. 8 Lateral External Pressure ............ 7-3

7. 2 Instability in the Inelastic Range $\ldots \ldots \ldots \ldots \ldots \ldots, 7-3$

7. 2. 1 Axial Compression ................. 7-3

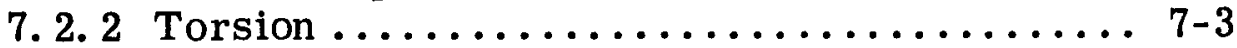

7. 2. 3 Bending ....................... 7-4

7. 2. 4 External Pressure $\ldots \ldots \ldots \ldots \ldots \ldots \ldots \ldots$ 7-4

7. 3 Instability due to Creep $\ldots \ldots \ldots \ldots \ldots \ldots \ldots \ldots \ldots, 7-4$

7.3.1 Axial Compression .................. 7-4

7.3. 2 Torsion ........................ 7-4

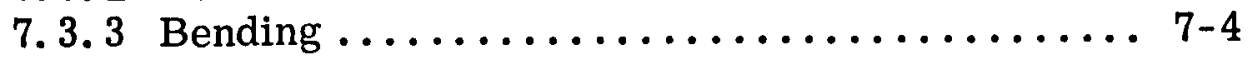

7.3.4 External Pressure $\ldots \ldots \ldots \ldots \ldots \ldots \ldots \ldots$ 7-5 
7. 4 Recommendations for Determining the Load Carrying Capacity of Piping Components such as Elbows, Returns, Laterals, Tee's, Pads for Hangers, Supports, etc .................. 7-5

7. 4. 1 Discussion of Applicable Methods ......... 7-5

8. BIBLIOGRAPHY $\ldots \ldots \ldots \ldots \ldots \ldots \ldots \ldots \ldots \ldots \ldots \ldots, 8,1$

\section{TABLES}

3.1 Comparison of Theory with Experimental Results -

Aluminum-Alloy Cylinders .................... 3-24

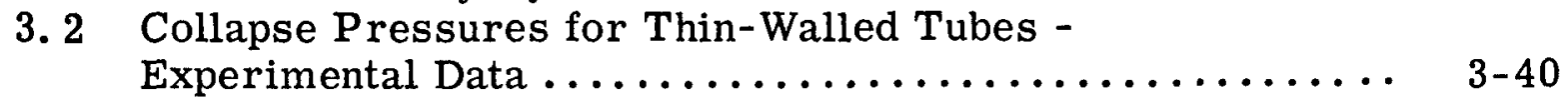

4.1 Discussion of Results and Conclusions -

Summary of Test Results . . . . . . . . . . . 4-3

\section{FIGURES}

1.1 Inter-Relationship Diagram - Task Area 3-8 -

Coolant Transport and Storage Systems . . . . . . . . 1-3

2.1(a) Effect of Residual Stress on Shell Buckling . . . . . . . 2-4

2.1(b)Comparison of Predictions and Test Results . . . . . 2-5

2.2 Comparison of Theoretical and Experimental Criticality Curves .. . . . . . . . . . . 2-6

2.3 Comparison of Experimental and Theoretical

Buckling Loads for Circular Cylindrical Shells under Axial Compression . . . . . . . . . . . 2-9

2.4 Length Changes of the Specimens vs Number of Cycles

3.1 Compressive Buckling Stress Coefficients as a Function of $\mathrm{r} / \mathrm{h}$. . . . . . . . . . . . 3-5

3.2 Comparison between Theoretical Solutions and Experiments .............. . 3-7

3.3 Creep End Shortening in Cylinder B 3-8

3.4 Maximum Deflection $w$ for a Cylinder under Axial Compression at Different Load Levels . . . . . . . 3-9

Increase in Compressive Buckling Stress
Due to Internal Pressure . . . . . . . . . 3-11

Variation of Axial-Stress Coefficient with
Internal Pressure Parameter . . . . . . . . . 3-12 
3.7 Comparisons of Experimental Dita with Theoretical Predictions . . . . . . . . . . . . . . 3-13

3.8 Creep End Shortening in Cylinder A . . . . . . . . . . . 3-15

3.9 Comparison of Theoretical Solutions and Experiments. . . 3-18

3.10 Upper and Lower Torsional Buckling Stress $\phi=\tau /(\mathrm{E} \sqrt{\eta})$ against $\mu \approx \pi(\mathrm{a} / \mathrm{l}) \sqrt[4]{\eta}$ Compared with Experimental Results . . . . . . . . . . . . . 3-19

3.11 Buckling Loads for Cylinders under Torsion Alone . . . . 3-20

3.12 Comparison of Experiment and Theory for the Buckling of Cylindrical Shells in Torsion and Corresponding Imperfection Sensitivity Angle . . . . . 3-21

3.13 Comparison of Theory with Experimental Results Steel Cylinders . . . . . . . . . . . . . . . . 3-23

3.14 Interaction Curve for Cylinders under Combined Torsion and External Lateral or Hydrostatic Pressure . . . . . . . . . . . . . 3-26

3.15 Buckling Loads for Cylinders under Combined Torsion and Hydrostatic Pressure . . . . . . . . . 3-27

3.16 Effect of Internal Pressure on Torsion Buckling Stress of Cylinders . . . . . . . . . . . . . 3-28

3.17 Unpressurized Bending Buckling Stress Coefficients as a Function of $\mathrm{r} / \mathrm{h}$. . . . . . . . . 3-30

3.18 Computed and Experimental Bending Modulus of Rupture Data - 260,000 U.T.S. Round Tubing . . . . . 3-32

3.19 Creep Buckling Curves for Four Cylinders under Bending ............... . 3-33

3.20 Increase in Bending Buckling Stress Coefficients Due to Internal Pressure . . . . . . . . . . . 3-34

3.21 Buckling Pressure of Cylinders with Small R/h Ratio . . 3-37

6.1 Comparison between Test Data and Calculated Results Using United Nuclear Computer Program CRE-BUCK . . 6-8 


\section{INTRODUCTION}

C. F. Braun \& Company, with United Nuclear Corporation as subcontractor, has been awarded a contract* by the United States Atomic Energy Commission for the development and verification of a Piping Design Guide for sodium-cooled fast breeder reactor power plants (LMFBR). The work is a Priority 1 Task under the LMFBR Program Plan $\dagger$ prepared for the USAEC Division of Reactor Development and Technology (RDT) by the LMFBR Program Office, Argonne National Laboratory. It is identified in the Program Plan as Task 3-8.2, Development of Design Technology for Piping.

This Technical Report critically reviews Instability Analysis Methods as related to LMFBR piping systems, with an aim toward selecting those theories and attendant analytical methods to form an adequate basis for criteria to insure structural adequacy for LMFBR piping systems.

A review procedure has been established to insure coordination of interdependent studies currently being performed under this and other task areas of the LMFBR Program Plan. Under the review procedure, the Liquid Metal Engineering Center (LMEC) is the coordinating agency. Technical Reports prepared by Braun under this contract will be distributed by LMEC to appropriate Review Agencies designated by the USAEC. Comments from Review Agencies will be evaluated by Braun/United Nuclear to determine their validity. Valid comments then will be incorporated into subsequent revisions to the Technical Reports.

*AT(04-3)-781, AEC San Francisco Operations Office (SAN). †Liquid Metal Fast Breeder Reactor Program Plan, LMFBR Program Office, Argonne National Laboratory - AEC R\&D Report, Reactor Technology, WASH-1101 (Aug. 1968). 
Fig. 1.1 shows the inter-relationship of tasks under Task Area 3-8. Coolant Transport and Storage Systems. 


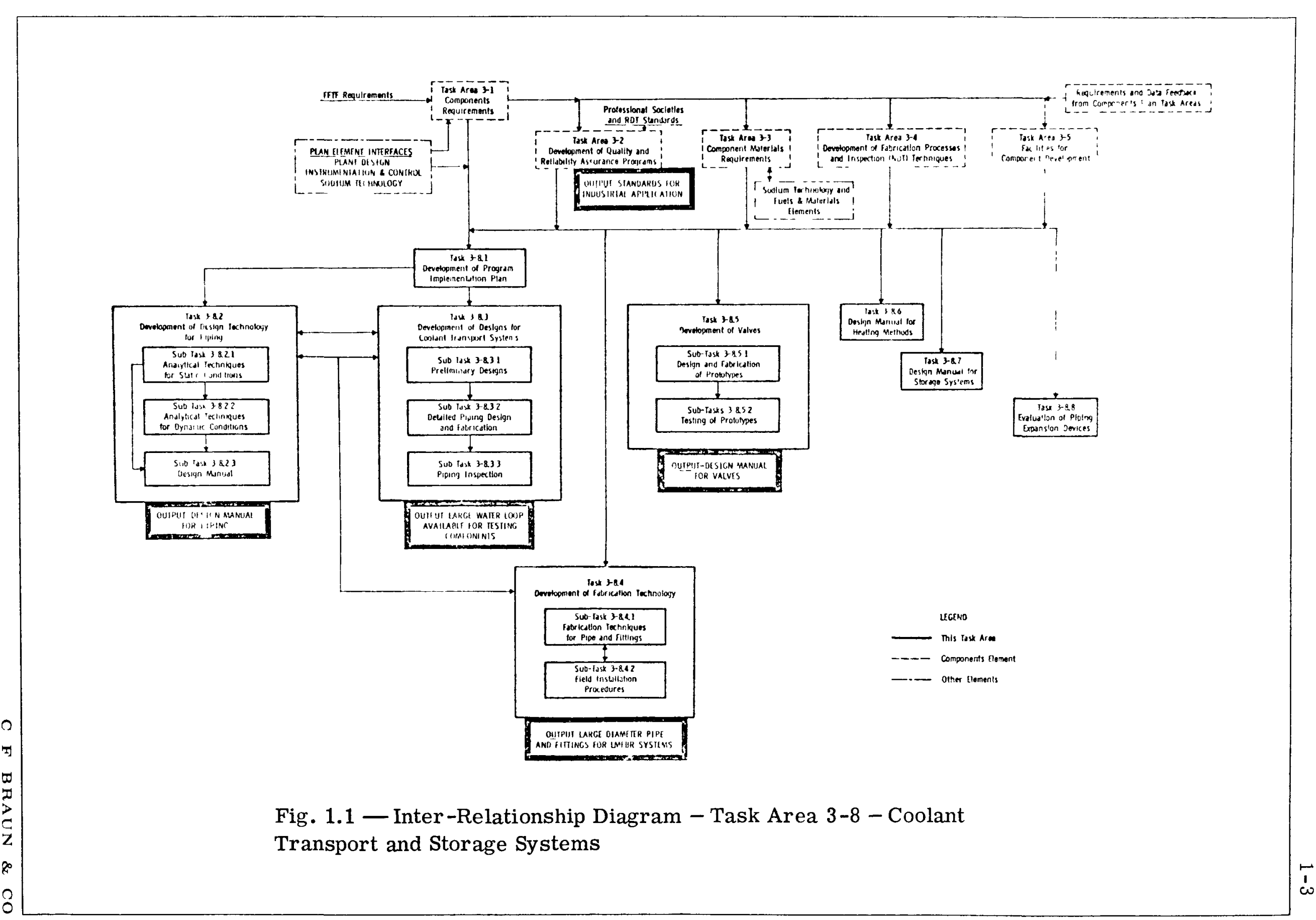




\section{GENERAL DISCUSSION}

The purpose of this report is to prepare a basis for the development of instability design criteria for thin-wall large diameter piping systems, such as the LMFBR piping system.

The scope of the report is the review of existing instability analysis methods, related computer programs, and experiments of a piping system under arbitrary loading, consisting of cylindrical tubes and local components such as elbows, returns, tubular connections, pads for hangers and supports, etc.

\subsection{DEFINITION OF INSTABILITY OR BUCKLING}

\subsubsection{Elastic Buckling}

The term elastic buckling usually means the occurrence of a marked change in the character of deformation of a shell which is not the result of any alteration of mechanical properties of the material. The phenomenon occurs in the region where the stress-strain relationships are still linear, i.e., below the elastic limit.

\subsubsection{Inelastic Buckling}

Inelastic buckling is the term applied to the deformation phenomenon described above when the elastic limit is exceeded before the inception of buckling. 


\subsubsection{Creep Buckling}

Under certain operational conditions (combinations of elevated temperature and stress) time-dependent deformation can occur in a structure due to the creep of the material. This behavior suggests that. in addition to the instantaneous buckling load, the design of such a structure must be based upon the time to reach an unstable deflection or bending moment, or upon some quantity related to these parameters. This time-dependent phenomenon of deformation to reach an unstable condition is referred to as creep buckling.

\subsection{CONDITIONS FOR INSTABILITY}

The case under review is a piping system which consists of straight and curved sections of stainless or $2 \frac{1}{4} \mathrm{Cr}-1 \mathrm{Mo}$ steel cylinders. The ratio of the mean radius to the wall thickness is in the range $<100$. In general, there are two types of sources which can cause instability.

1. The Primary Sources
a. Axial loads (tension and compression)
b. Bending and torsional moments
c. External and internal pressure
d. Combinations of items a through c.

2. The Secondary Sources
a. Residual stresses
b. Dynamic load
c. Temperature.

The instability behavior under the primary loading sources is described in Sections 3 and 4.

The secondary sources are more complex and analysis methods are in the state of early development. In general, the effect of these sources on the instability resistance of the piping system should be covered by the margin of safety. Some of these effects are indicated below and recommended development work is described in Section 5.

The effect of the temperature on the instability resistance is covered in the analysis methods for creep buckling. But this is only for uniform temperature. In the presence of nonuniform temperature distribution 
the instability resistance will be reduced. Any approximate calculation of the reduction requires an exact knowledge of the nonuniformity of the temperature as discussed in Section 5.

Residual stresses are introduced by forming processes in fabrication and by welding. The effect of residual stresses on the buckling pressure for tubes under external pressure was investigated by Haskell in Reference 1. The influence of the residual stresses on the inelastic and elastic buckling pressure is shown in Fig. 2.1. Further information is needed for a full understanding of this effect.

The dynamic stability in a cylindrical shell was analyzed by Ogibalov in Reference 2. The conclusion of his analysis is that a dynamic load can act as a superimposed restraint making the tube more stable. He defines an overloading coefficient which increases with increasing loading velocity and decreasing initial deflection. A theoretical and experimental investigation of dynamic pulse buckling was done by Anderson and Lindberg in Reference 3. The increase of the critical load vs time is shown in Fig. 2.2. The development work recommended to this subject is described in Section 5 .

\subsection{PRESENT THEORY STATE-OF-THE-ART}

\subsubsection{Elastic Instability}

Recently developed analysis methods are based on nonlinear shell theory. The nonlinearity enters through nonlinear terms in the displacement function. For some loading conditions, digital computer programs are developed based on nonlinear shell theory; but no program is developed for unlimited arbitrary loading. The available computer codes are described in detail in Section 6. Conclusions about the conservatism of these computer programs are not possible at this time. A detailed check of the accuracy of the programs is a prerequisite to recommending their use in design of LMFBR piping, and is recommended as a future development item.

The different analysis methods based on linear shell theory are described in Section 3 and the poor agreement with experimental results is shown. For some loading conditions, such as bending or pressure in combination with other loads, even the theories give contradictory results. 


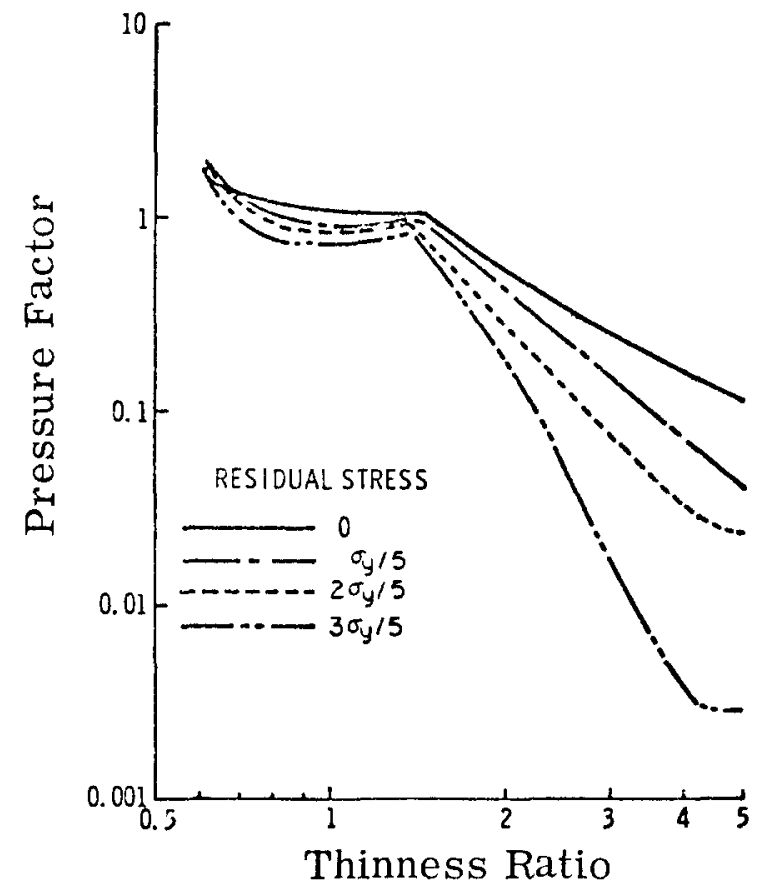

Fig. 2.1(a) - Effect of Residual Stress on Shell Buckling

$$
\text { Thinness Ratio } \begin{aligned}
& =-\sqrt{\frac{(\ell / 2 \mathrm{r})^{2}}{(\mathrm{~h} / 2 \mathrm{r})^{3}}} \cdot \sqrt{\sigma_{\mathrm{y}} / \mathrm{E}} \\
\ell, \mathrm{r}, \mathrm{h} & =\text { shell length, radius, thickness } \\
\sigma_{\mathrm{y}} & =\text { yield stress } \\
\mathrm{E} & =\text { modulus of elasticity }
\end{aligned}
$$

Pressure Factor $=\frac{\mathrm{p}}{(\mathrm{h} / \mathrm{r}) \sigma_{\mathrm{y}}}$

$$
\mathrm{p}=\text { buckling pressure }
$$




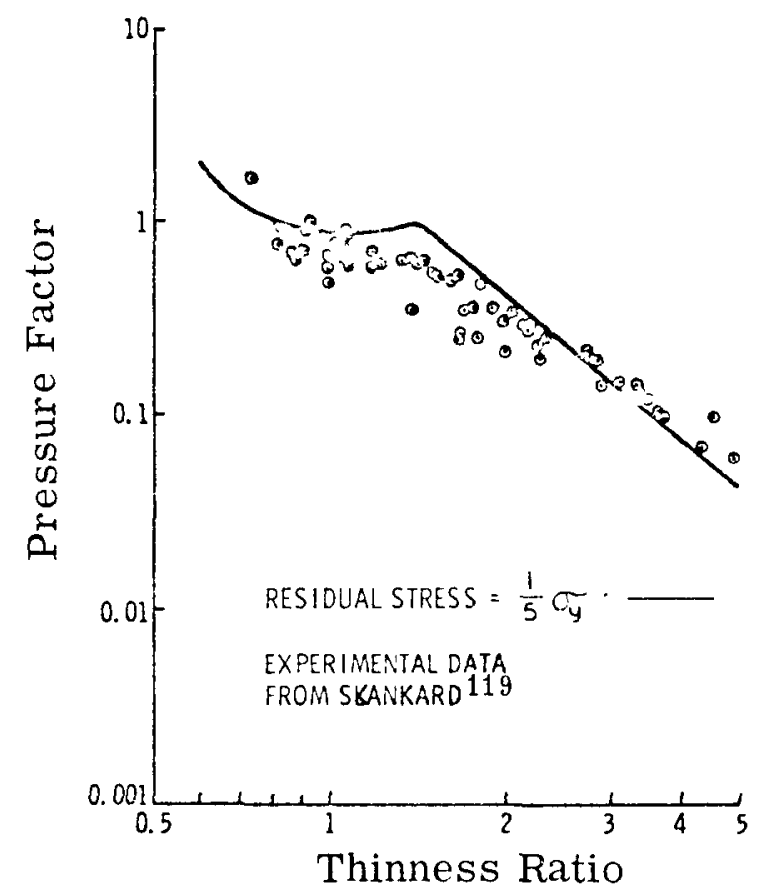

Fig. 2.1(b) - Comparison of Predictions and Test Results

$$
\text { Thinness Ratio } \begin{aligned}
& =\sqrt[4]{\frac{(\ell / 2 \mathrm{r})^{2}}{(\mathrm{~h} / 2 \mathrm{r})^{3}}} \cdot \sqrt{\sigma_{\mathrm{y}} / \mathrm{E}} \\
\ell, \mathrm{r}, \mathrm{h} & =\text { shell length, radius, thickness } \\
\sigma_{\mathrm{y}} & =\text { yield stress } \\
\mathrm{E} & =\text { modulus of elasticity }
\end{aligned}
$$$$
\text { Pressure Factor }=\frac{p}{(h / r) \sigma_{y}}
$$$$
\mathrm{p}=\text { buckling pressure. }
$$ 


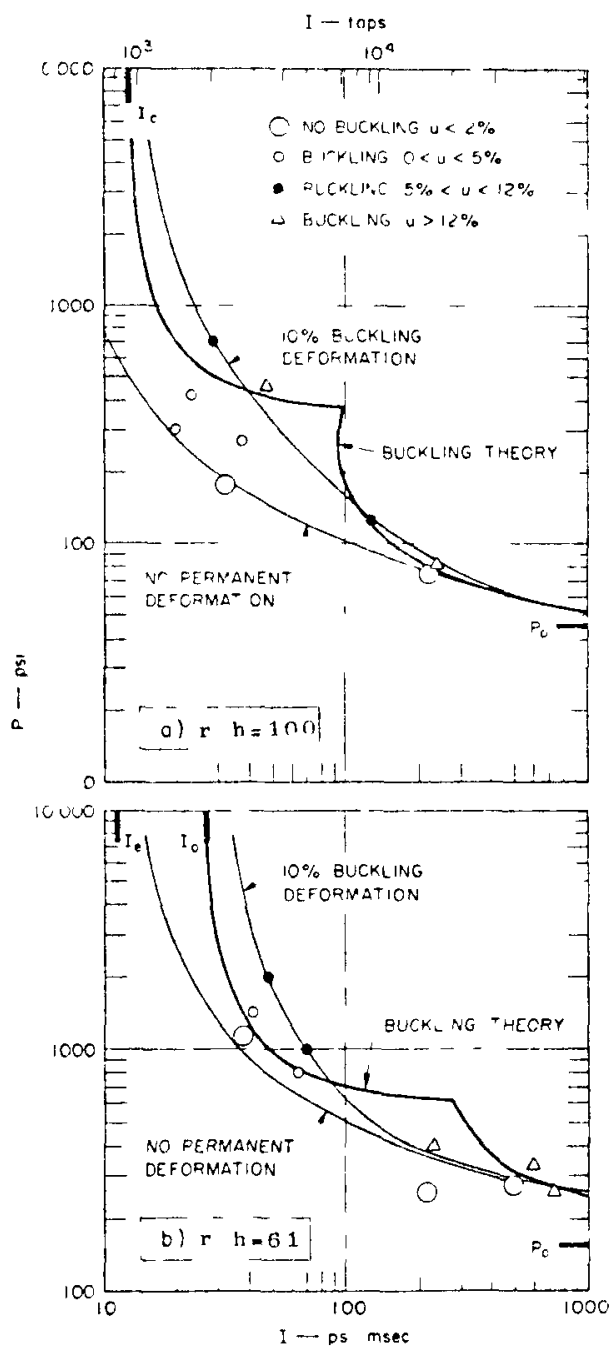

Fig. 2.2 - Comparison of Theoretical and Experimental Criticality Curves (Exponential pulses, 6061-T6 aluminum, $\mathrm{D}=6$ in., $\mathrm{L} / \mathrm{D}=1$ ).

$$
\begin{aligned}
\mathrm{u}=\frac{\mathrm{w}}{\mathrm{r}} & =\text { dimensionless displacement } \\
\mathrm{w} & =\text { radial displacement } \\
\mathrm{r} & =\text { mean radius. }
\end{aligned}
$$




\subsubsection{Inelastic Instability}

Most of the analysis methods for inelastic buckling use the tangent modulus approach. This means the modulus of elasticity is replaced by the tangent modulus which varies with the stress. The ASME Code design charts for external pressure are based on this approach. In general, linear theory of elasticity is used and the result is corrected by a plasticity reduction factor. More advanced theories are needed to get a better accuracy of the results. Such analysis methods are given by Corum ${ }^{4}$ for external pressure, by Ades ${ }^{5}$ for bending, and by Battermann $^{6}$ for axial compression, as described in Section 3 .

\subsubsection{Creep Instability}

The most important factor for creep instability analysis methods is the uncertainty of the creep data. The simplification of the creep behavior of the material, which is done in all analysis methods, results in a lesser degree of accuracy of the analysis method. Because of the time dependence, a proper analysis method should be based on a time-dependent stress-strain characteristic and the resulting straintime characteristic.

The existing analysis methods are still in the development stage. In general, there is poor agreement between theory and experiment. Comparisons between theory and experiment should include the entire range of deformation up to failure, since compensating effects inherent in creep behavior may make it possible to obtain close agreement between theory and experiment for creep strain or deformation at failure, even if there is poor agreement between predicted and observed deformations prior to failure.

A computer program which is useful in creep instability problems involving external pressure is CRE-BUCK described in Section 6.

\subsection{PRESENT STATE-OF-THE-ART OF EXPERIMENTS}

\subsubsection{Elastic Instability}

The wide scattering of the experimental results shows that some improvement of the experiments is necessary. In most cases the initial imperfections were not measured and the results are useless for com- 
parison with the theory, but still very useful to show the average buckling load for initial imperfect shells. An evaluation of all experimental results was done by Stein in Reference 7 for cylinders under axial compression. The results are shown in Fig. 2.3. The author presented results of recently conducted experiments on near-perfect shells which were in good agreement with the theory.

\subsubsection{Inelastic Instability}

There is a relatively small amount of experimental data available on inelastic buckling. In general, the experimental investigations are better performed than the tests for elastic instability. It seems that the effect of small initial imperfections on the critical buckling load is not as great as in the case of elastic buckling. The available test data are shown in Sections 3 and 6.

\subsubsection{Creep Instability}

A small amount of experimental data on creep instability exists only for external pressure, axial compression, and bending. The results are shown in Sections 3 and 6 . An investigation about the thermal strain cycling behavior including creep and relaxation effect was performed at AEG in Germany and reported by Schwarzwaelder and Wolf in Reference 8. The length shortening of a cylinder under cycling axial thermal load is shown in Fig. 2.4. 


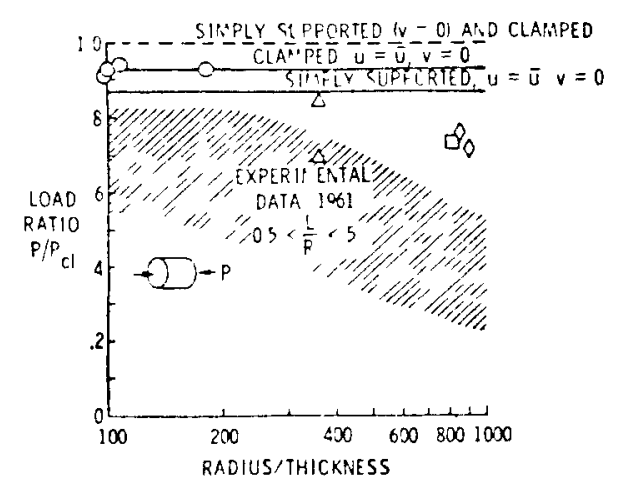

Fig. 2.3 - Comparison of Experimental and Theoretical Buckling Loads for Circular Cylindrical Shells under Axial Compression

$\mathrm{u}, \mathrm{v}=$ displacements in the meridional and circumferential directions

- - - = linear theory

$-=$ nonlinear theory 


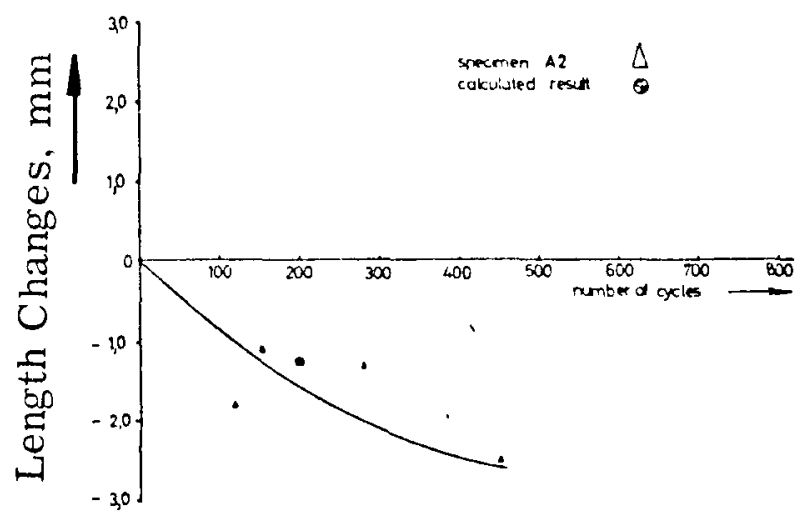

a. Specimens of Test Series A

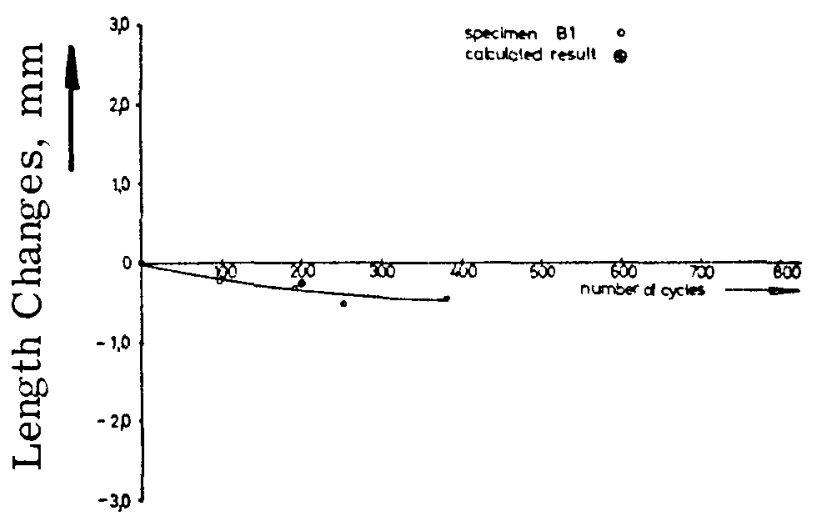

b. Specimens of Test Series B

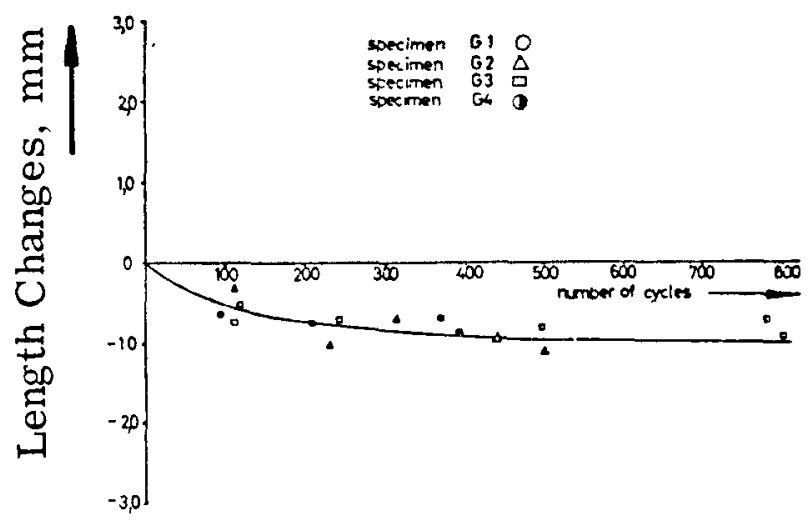

c. Specimens of Test Series G

Fig. 2.4 - Length Changes of the Specimens vs Number of Cycles 
3. REVIEW OF ANALYSIS METHODS AND EXPERIMENTAL DATA FOR STRAIGHT PIPE UNDER VARIOUS LOADING CONDITIONS

\subsection{CYLINDER UNDER AXIAL LOADING}

\subsubsection{Cylinder under Axial Compression Only}

It is well known that for unpressurized thin-walled cylinders large discrepancies exist between values of the critical buckling load determined by experiment and those predicted by linear theory of elasticity (small-deflection theory). The experimental values of the critical load are always only a fraction of the calculated theoretical critical load, dependent on the radius-to-thickness ratio, $R / h$.

In the case of LMFBR piping, the $\mathrm{R} / \mathrm{h}$ ratio $<100$; therefore, buckling can occur either in the inelastic range or in the elastic range.

\section{A. Elastic Buckling}

The "classical" small-deflection theory gives the buckling stress, $\sigma_{\mathrm{cr}}$, as

$$
\sigma_{\mathrm{cr}}=\frac{\mathrm{N}_{\mathrm{cr}}}{\mathrm{h}}=\frac{\mathrm{Eh}}{\mathrm{R} \sqrt{3\left(1-\nu^{2}\right)}}
$$

where $\mathrm{E}=$ modulus of elasticity

$\mathrm{h}=$ wall thickness

$\mathrm{R}=$ mean radius

$\mathrm{N}_{\mathrm{cr}}=$ critical buckling load (lb/in. of circumference). 
$\sigma_{\text {cr }}$ - actually the stress in the unbuckled resion.

To obtain better agreement with experimental data, ron Karman and Tsien ' developed a large deflection theory by showing the existence of a large deflection equilibrium configuration at a lower stress than that calculated by small deflection theory. This theor used nonlinear shell theory and shows better agreement with experiments. but still predicts critical buckling loads that are too high. The nomlinearity enters throus the large deflection which induces membrane strosses in the shell. Refinements of the von Karman-Tsien theory were made by Kempner" and Almroth, " but they only established better agrement in the post-buckling region which is beyond the scope of this report.

A large deflection theory including initial imperfectuons was developed by Donnell and Wan, ${ }^{12}$ taking into account the fact that the initial imperfections are usually the same size as the small buckles generated at critical load. In this theory the basic differential equations of equilibrium for a cylinder are:

$$
\begin{aligned}
& N_{x, x}+N_{x y, y}=0 \\
& N_{y, y}+N_{x y, x}=0 \\
& D \nabla^{4} w=p+N_{x} \frac{\partial^{2} w}{\partial x^{2}}+2 N_{x y} \frac{\partial^{2} w}{\partial x \partial y}+N_{y} \frac{\partial^{2} w}{\partial y^{2}}+\frac{N_{y}}{R}
\end{aligned}
$$

These equations represent the summation of the forces in the axial, circumferential, and radial directions.

According to Hooke's law, the membrane stress resultants are:

$$
\begin{aligned}
& \left.\mathrm{N}_{\mathrm{x}}=\frac{\mathrm{Eh}}{1-\nu^{2}}\right]\left(\epsilon_{\mathrm{x}}+\nu \epsilon_{\mathrm{y}}\right) \\
& \mathrm{N}_{\mathrm{y}}=\left[\frac{\mathrm{Eh}}{1-\nu^{2}} ;\left(\epsilon_{\mathrm{y}}+\nu \epsilon_{\mathrm{x}}\right)\right. \\
& \left.\mathrm{N}_{\mathrm{xy}}=-\frac{\mathrm{Eh}}{2(1-\nu)}\right] \gamma_{\mathrm{xy}}
\end{aligned}
$$


The nonlinear strain-displacement relations on the middle surface of the thin circular cylinder of radius $R$ are:

$$
\begin{aligned}
& \epsilon_{\mathrm{x}}=\frac{\partial \mathrm{u}}{\partial \mathrm{x}}+\frac{1}{2}\left(\frac{\partial \mathrm{w}}{\partial \mathrm{y}}\right)^{2} \\
& \epsilon_{\mathrm{y}}=\frac{\partial \mathrm{v}}{\partial \mathrm{y}}+\frac{1}{2}\left(\frac{\partial \mathrm{w}}{\partial \mathrm{y}}\right)^{2}-\frac{\mathrm{w}}{\mathrm{R}} \\
& \gamma_{\mathrm{xy}}=\frac{\partial \mathrm{u}}{\partial \mathrm{y}}+\frac{\partial \mathrm{v}}{\partial \mathrm{x}}+\frac{\partial \mathrm{w}}{\partial \mathrm{x}} \frac{\partial \mathrm{w}}{\partial \mathrm{y}}
\end{aligned}
$$

where $N_{x}, N_{x y}, N_{y}=$ the membrane stress resultants

$$
\begin{aligned}
\mathrm{p}= & \text { radial external pressure } \\
\mathrm{u}, \mathrm{v}, \mathrm{w}= & \text { displacements in the } \mathrm{x}-, \mathrm{y}-, \text { and radial } \\
& \text { directions, respectively } \\
\mathrm{x}, \mathrm{y}= & \text { meridional and circumferential directions } \\
\mathrm{D}= & \frac{\mathrm{Eh}^{2}}{12\left(1-\nu^{2}\right)}=\text { flexural rigidity of the wall } \\
\mathrm{R}= & \text { cylindrical radius of shell at midthickness } \\
\nabla^{4}= & \left(\frac{\partial^{4}}{\partial \mathrm{x}^{4}}\right)+\left(2 \frac{\partial^{4}}{\partial \mathrm{x}^{2} \partial \mathrm{y}^{2}}\right)+\left(\frac{\partial^{4}}{\partial \mathrm{y}^{4}}\right) \\
\nu= & \text { Poisson's ratio } \\
\epsilon_{\mathrm{x}}, \epsilon_{\mathrm{y}}, \gamma_{\mathrm{xy}}= & \text { strains } \\
\mathrm{E}= & \text { Young's modulus for material. }
\end{aligned}
$$

These sets of equations (Eqs. 3.2 through 3.4) provide a complete set of nine equations for nine unknown stress resultants, strains, and displacements. These, together with the boundary conditions, specify the problem. An extensive number of experimental investigations was made by North American Aviation, Inc. The results of these experiments are published in Reference 13 along with experimental results of 
other investigations. Fig. 3.1 shows the experimental results. It is clearly seen from this plot that the difference between linear buckling theory and experiment increases with increasing $R / h$ ratio. These results are evaluated with statistical methods to establish design curves. A $90 \%$ and $99 \%$ probability curve along with the best fit curve are shown in Fig. 3.1.

Recent investigations by Stein ${ }^{7}$ show that in case of very carefully prepared experiments there is good agreement between theory and experiment in the lower $\mathrm{R} / \mathrm{h}$ ratios. (See Fig. 2.3.) He believes that the initial imperfections are the main reason for the discrepancies between theory and experiment. With respect to the uncertainties in the theories, the statistical evaluation of experimental results seems to be the only method to provide conclusions over the conservatism of the design method. Excellent papers considering the use of statistical methods in the theory of stability of plates and shells are given by Bolotin and Vorovich in Reference 14. Computer programs for nonlinear analysis of shells subject to arbitrary loading have been developed by Lockheed Missiles and Space Company and by NASA Spacecraft Center with Sandia Corporation and Texas A\&M University. ${ }^{64-70}$ The programs are described in Section 6.1.

\section{B. Inelastic Buckling}

In the case of inelastic buckling, the modulus of the material becomes a function of the stress and decreases as the stress increases above the elastic limit. This causes a decrease of the stiffness of the shell and a corresponding decrease in the buckling load. Analysis methods for inelastic buckling of axially compressed cylinders are given by Bijlaard, ${ }^{15}$ Gerard, ${ }^{16,17}$ and Battermann. ${ }^{6,18}$

Gerard established plasticity reduction factors which are based on Bijlaard's work. For a cylinder under axial compression, the plasticity reduction factor $\eta$ is given by

$$
\eta=\left(\frac{1-\nu_{\mathrm{e}}^{2}}{1-\nu^{2}}\right)^{1 / 2} \times \frac{\mathrm{E}_{\mathrm{S}}}{\mathrm{E}} \times\left(\frac{\mathrm{E}_{\mathrm{t}}}{\mathrm{E}_{\mathrm{S}}}\right)^{1 / 2}
$$

where $\mathrm{E}=$ modulus of elasticity

$\mathrm{E}_{\mathrm{S}}=$ secant modulus 


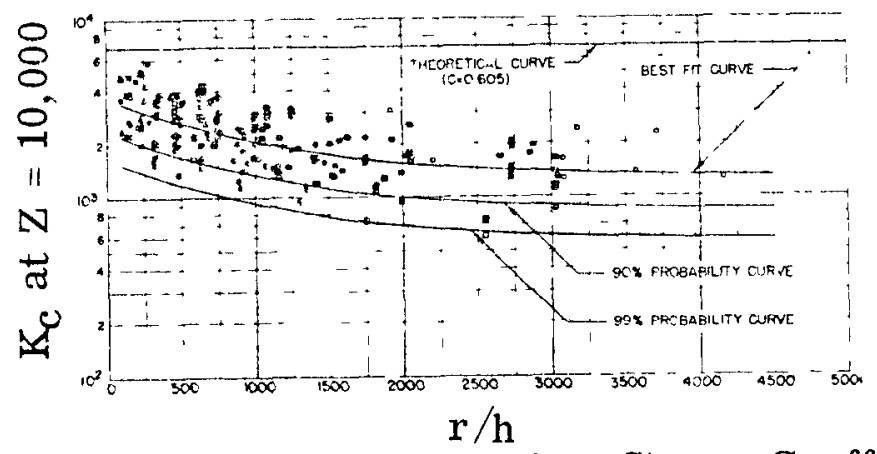

Fig. 3.1-Compressive Buckling Stress Coefficients as a Function of $\mathrm{r} / \mathrm{h}$ (semilogarithmic grid)

$\mathrm{K}_{\mathrm{C}}$ = buckling stress coefficient in the equation

$$
\begin{aligned}
\frac{\sigma_{\mathrm{Cr}}}{\eta} & =\mathrm{K}_{\mathrm{C}}\left[\pi^{2} \mathrm{E} / 12\left(1-\nu^{2}\right)\right]\left(\mathrm{h}^{2} / \mathrm{L}^{2}\right) \\
\mathrm{Z} & =\text { curvature parameter }=\left(\mathrm{L}^{2} / \mathrm{rh}\right) \sqrt{1-\nu^{2}} \\
\eta & =\text { plasticity correction factor. }
\end{aligned}
$$




$$
\begin{aligned}
\mathrm{E}_{\mathrm{t}} & =\text { tangent modulus } \\
\nu & =\text { Poisson's ratio } \\
\nu_{\mathrm{e}} & =\text { elastic value of Poisson's ratio. }
\end{aligned}
$$

Now the actual buckling stress is determined by:

$$
\sigma_{\mathrm{cr}}=\eta \times \sigma_{\mathrm{e}}
$$

where $\sigma_{\mathrm{e}}=$ elastic buckling stress.

The theory of Battermann also uses the variation of the tangent modulus with the stress and is based on the "Distortion Energy Theory", which is associated with the names of von Mises, Huber, and Hencky. The theory shows fairly good agreement with experimental results, as shown in Fig. 3.2.

\section{Creep Buckling}

Analysis methods for creep buckling of a cylindrical shell under axial compression are given by Hoff, ${ }^{19}$ Diamant, ${ }^{20}$ and Samuelson. ${ }^{21,22}$ Diamant uses a digital computer program to calculate the deformation behavior of a cylinder under axial compression. A comparison between theory and experiment is shown in Fig. 3.3. A simpler theory is presented by Samuelson which includes plasticity effects in addition to elastic deformation and creep. A comparison between theory and experiment is shown in Fig. 3.4.

Hoff developed equations in his theory from which the time-dependent deformations of long cylinders with initial imperfections can be calculated.

The critical time for creep buckling is given as:

$$
t_{c r}=0.588 h_{E} \log \frac{1440}{a / h^{*}}
$$

where a $=$ radius of middle surface,

$\mathrm{h}^{*}=$ wall thickness, and

$$
\mathrm{h}_{\mathrm{E}}=\frac{\epsilon_{\mathrm{E}_{\mathrm{I}}}}{\dot{\epsilon}_{\text {nom }}}
$$




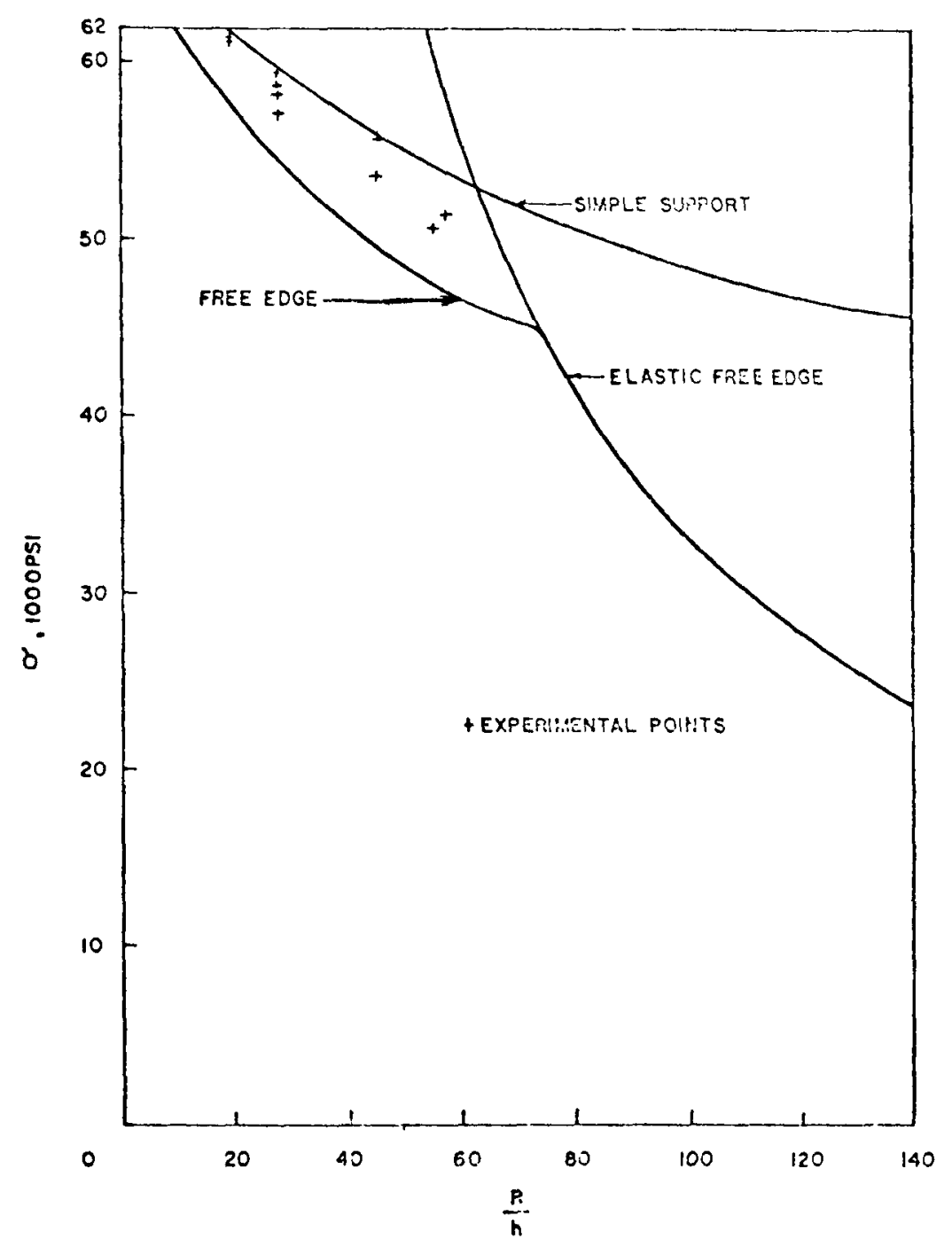

Fig. 3.2 - Comparison between Theoretical Solutions and Experiments 


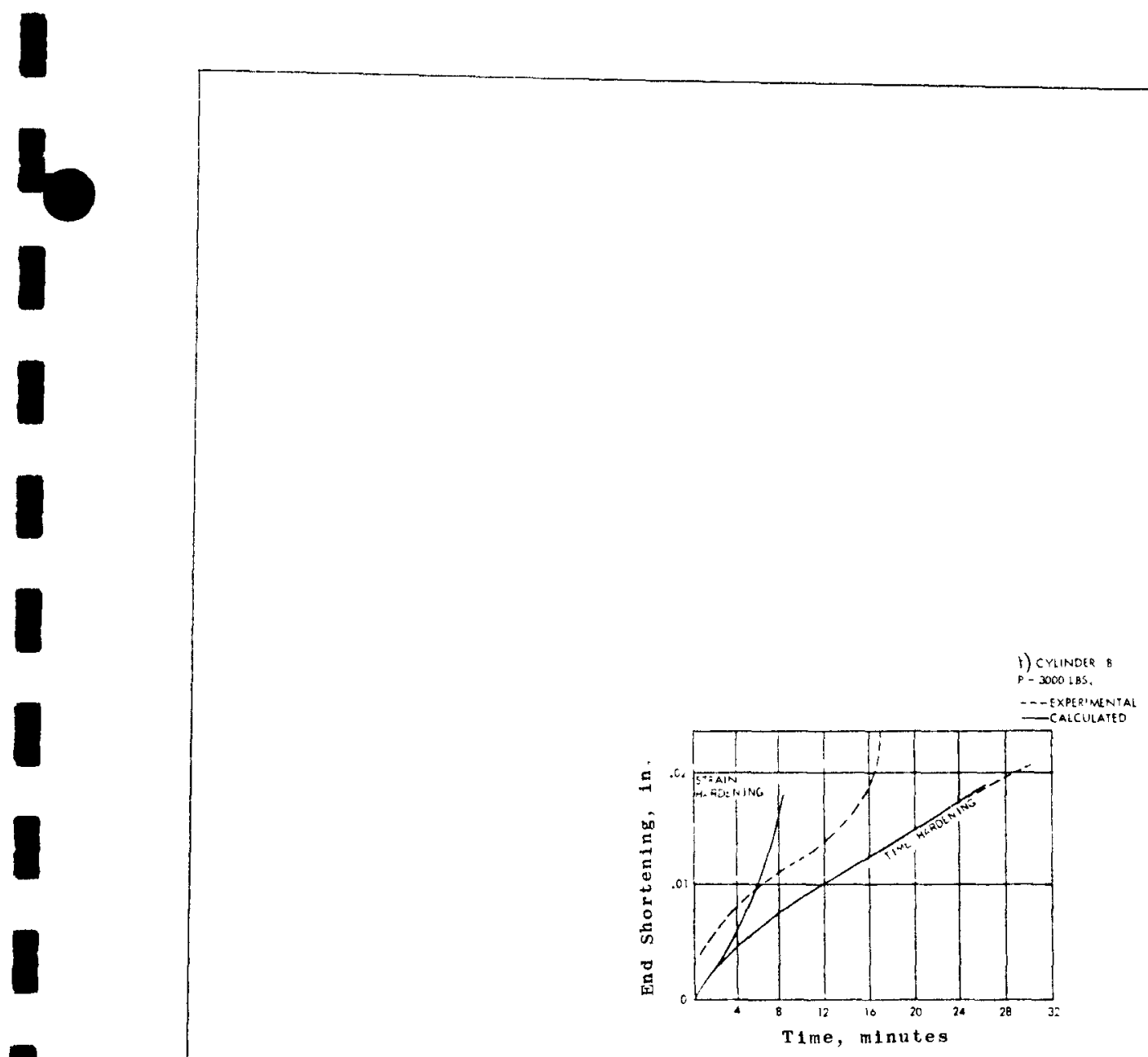

Fig. 3.3 - Creep End Shortening in Cylinder B 


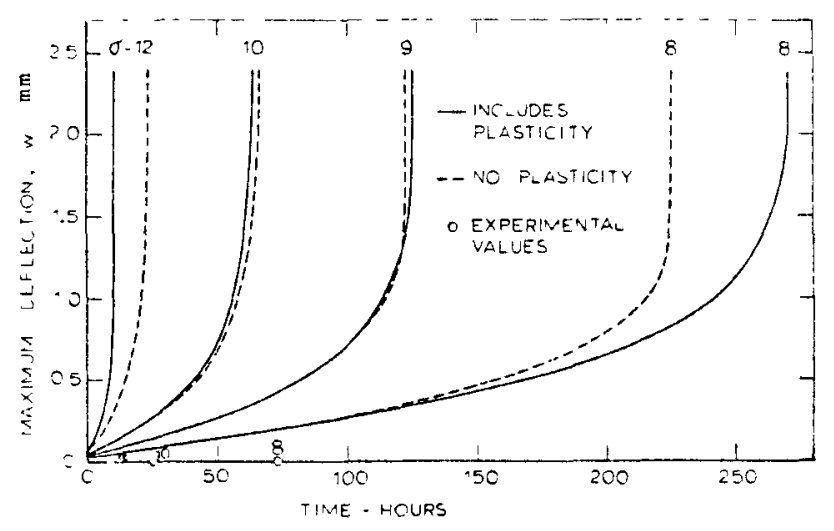

Fig. 3.4 - Maximum Deflection w for a Cylinder under Axial Compression at Different Load Levels 


$$
\begin{aligned}
\epsilon_{\mathrm{E}} & =0.6 \times \frac{\mathrm{h}^{*}}{\mathrm{a}} \\
\dot{\epsilon}_{\text {nom }} & =\mathrm{B} \times \mathrm{p}^{3}=\text { nominal strain rate calculated from creep law } \\
\mathrm{p} & =\text { axial compressive load } \\
\mathrm{B} & =\text { material constant. }
\end{aligned}
$$

Before these simple solutions can be applied. a check against experimental results must be made.

\subsubsection{Cylinder under Axial Compression Including Internal Pressure}

Theoretical investigations into this subject are done by Flügge ${ }^{23}$ and Lo et al. ${ }^{24}$ The results are contradictory. Whereas Flügge shows in his theory that there is no increase of the buckling load due to internal pressure using small-deflection theory, Lo et al. calculate an increase due to internal pressure of the buckling coefficient to the classical value of 0.605 , assuming Poisson's ratio as 0.3 . This was done using an extension of the large-deflection theory of von Karman and Tsien. ${ }^{9}$ The theory of Lo et al. is in fairly good agreement with their experimental results, and with results of other investigators, as shown in Fig. 3.5.

The theoretical curve for the increase of the buckling stress was generated using a $90 \%$ probability design curve for the unpressurized cylinder and subtracting this value from the buckling stress of the pressurized cylinder. A more recent extensive and accurate experimental investigation by Weingarten et al. ${ }^{25}$ shows excellent agreement with Lo's theory, Fig. 3.6.

The experimental results by Weingarten et al. were evaluated by Hutchinsen ${ }^{26}$ with respect to the initial imperfections, asymmetric or axisymmetric. He shows that in the case of axisymmetric imperfections, the increase of the buckling stress is not as large as the increase in the case of asymmetric imperfections, Fig. 3.7. This is in good agreement with theory that for an axial compressed cylinder without internal pressure, the axisymmetric imperfections are the more dangerous ones.

An analysis which predicts the creep buckling of a cylinder under axial compression including internal pressure was developed by 


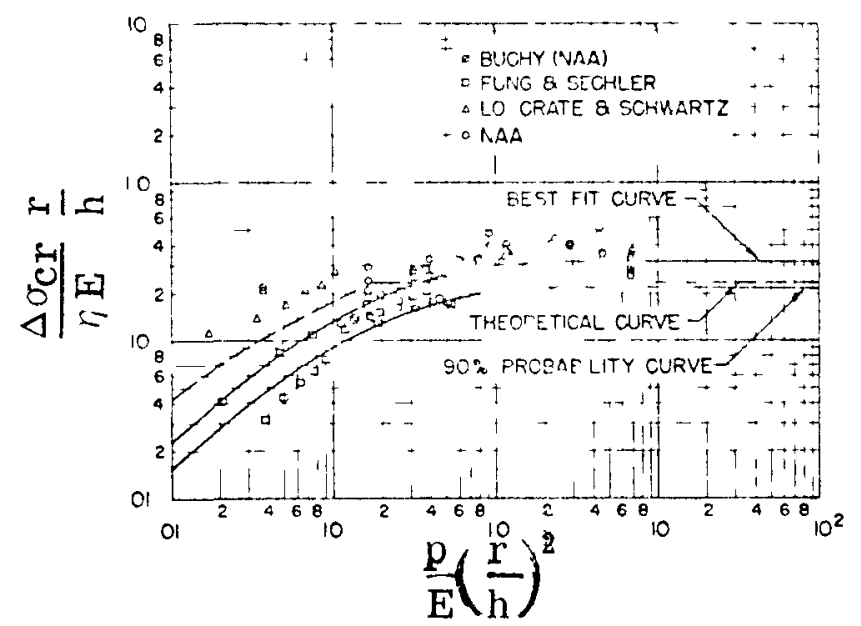

Fig. 3.5 - Increase in Compressive Buckling Stress Due to Internal Pressure 
a)

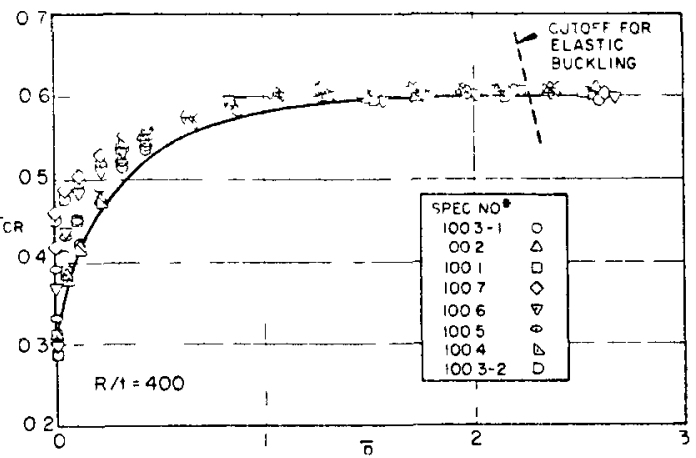

Numbers correspond to tabulated data given

In Reference 25

b)

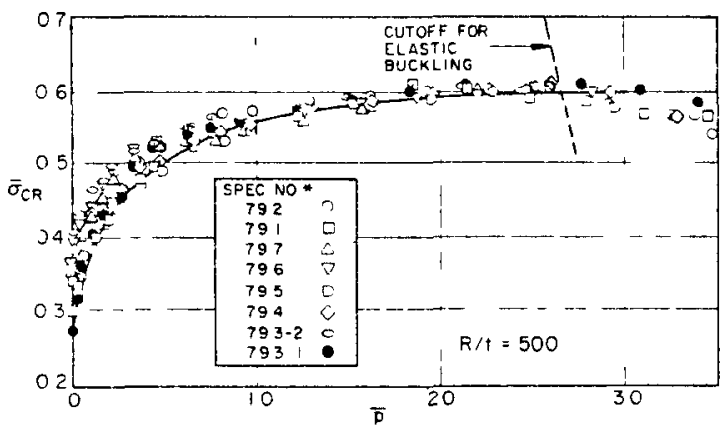

"Numbers correspond to tabulated data given in Reference 25 . c)

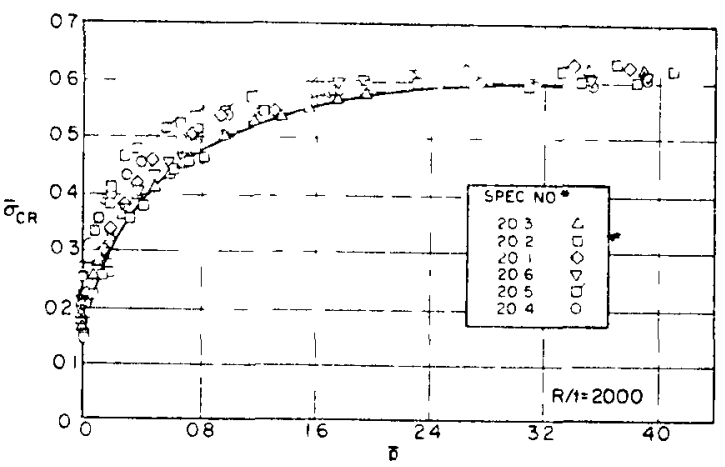

Numbers correspond to tabulated data given 1.n Reference 25

d)

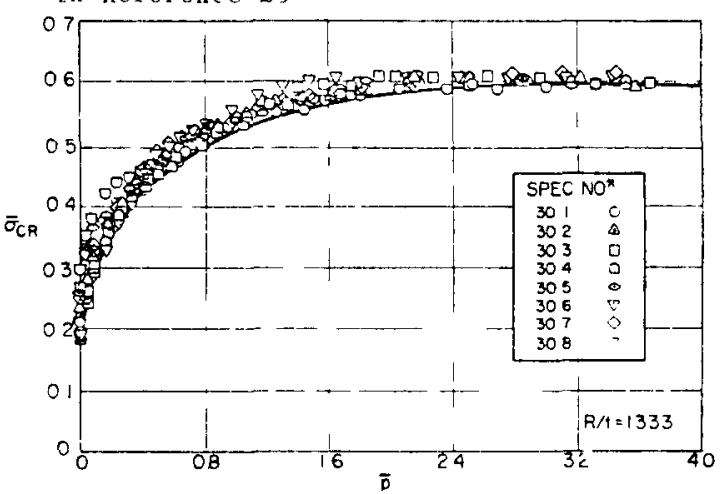

"Numbers correspond to tabulated data given in Reference 25.

Fig. 3.6 - Variation of Axial-Stress Coefficient with Internal Pressure Parameter 


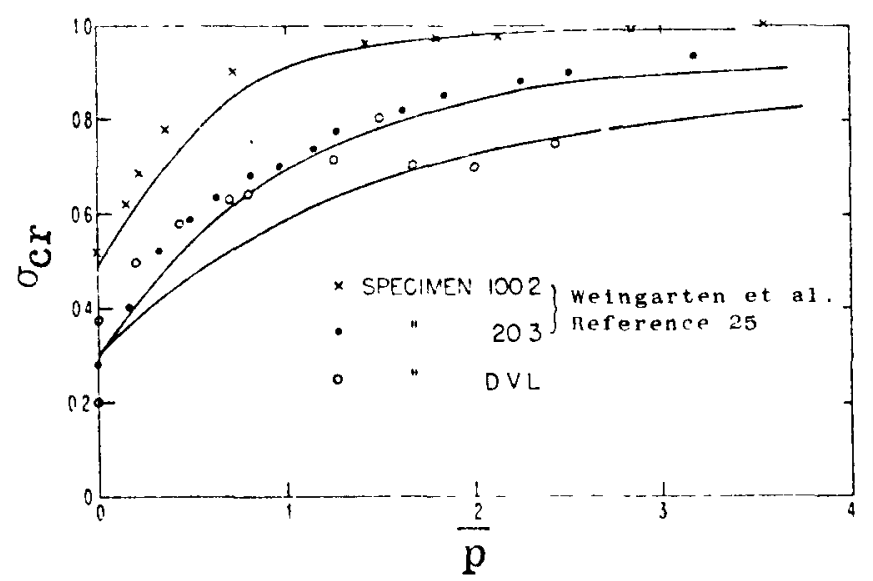

Fig. 3.7 - Comparisons of Experimental Data with Theoretical Predictions 
E. S. Diamant using time- and strain-hardening creep laws. A comparison with an experiment shows a conservative prediction using strain hardening, whereas time hardening comes closer to the experimental result. (See Fig. 3.8.)

\subsubsection{Cylinder under Axial Compression Including External Pressure}

A theoretical solution to this subject was worked out by Timoshenko and Gere in Reference 27. The theory shows that the critical value of the lateral pressure decreases due to increasing axial compressive load. Further information is required to substantiate any recommendation regarding the buckling behavior under combinations of axial compression and external pressure. Development of this information is included in the development recommendations of Section 5 .

\subsubsection{Cylinder under Axial Tension and Combined with Internal Pressure}

The biaxial-tension behavior of thin-walled cylinders was investigated by Jones. ${ }^{28}$ In the case of axial tension or axial tension combined with internal pressure, instability occurs prior to fracture. The important result from these investigations is that the strain due to instability (fracture) under uniaxial circumferential stress is lower than under uniaxial tension. The specimens for the experimental investigations were made of nickel-chrome corrosion-resisting steel. The plastic analysis of instability under internal pressure and axial load has been discussed by Bert ${ }^{30}$ and Bert et al.$^{29}$ described the effect of variation in Poisson's ratio on plastic tensile instability.

\subsection{CYLINDER UNDER TORSION}

As in the case of an axially compressed cylinder, the classical theory predicts too high a buckling stress for a cylinder under torsion. The differences between theory and experiments are not as great as in axial compression, but still are significant. The effects of internal and external pressure are the same as for a cylinder in axial compression. Internal pressure increases the buckling load whereas external pressure decreases the buckling load. 


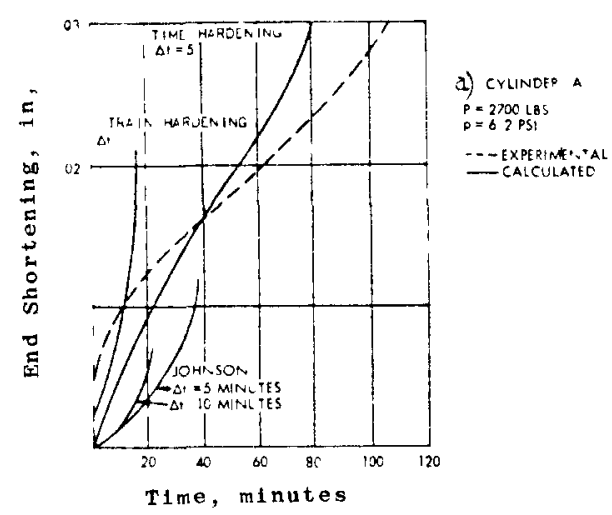

Fig. 3.8 - Creep End Shortening in Cylinder A 


\subsubsection{Cylinder under Torsion Only}

A. Elastic Buckling

The derivation of the buckling stress for a cylinder under torsion is given by Timoshenko, ${ }^{27}$ based on the work by Schwerin. ${ }^{31}$ The critical torsional shear-stress for an infinitely long cylinder is given by:

$$
\tau_{\mathrm{cr}}=\frac{\mathrm{M}_{\mathrm{Cr}}}{2 \pi \mathrm{R}^{2} \mathrm{~h}}=\frac{\mathrm{E}}{3 \sqrt{2}\left(1-\nu^{2}\right)^{3 / 4}} ; \frac{\mathrm{h}}{\mathrm{R}} i^{3 / 2}
$$

This equation was modified for short and moderately long cylinders considering end effects by Donnell. He obtained the following equations for the critical shearing stress:

$$
\tau_{\mathrm{cr}}=\frac{\mathrm{E}}{\left(1-\nu^{2}\right)}\left(\frac{\mathrm{h}}{\ell}\right)^{2}\left[4.6+\sqrt{7.8+1.67\left(\sqrt{1-\nu^{2}} \frac{\ell^{2}}{2 \mathrm{Rh}}\right)^{3 / 2}}\right]
$$

for clamped edges, and

$$
\tau_{\mathrm{cr}}=\frac{\mathrm{E}}{\left(1-\nu^{2}\right)}\left(\frac{\mathrm{h}}{\ell}\right)^{2}\left[2.8+\sqrt{2.6+1.40\left(\sqrt{1-\nu^{2}} \frac{\ell^{2}}{2 \mathrm{Rh}}\right)^{3 / 2}}\right]
$$

for simply supported edges,

where $\mathbf{E}=$ modulus of elasticity

$\nu=$ Poisson's ratio

$\ell=$ length of cylinder

$\mathbf{R}=$ mean radius of cylinder

$\mathrm{h}=$ wall thickness of cylinder.

Using

$$
\sqrt{1-\nu^{2}} \times \frac{\ell^{2}}{2 \mathrm{Rh}}
$$

and

$$
\left(1-\nu^{2}\right) \frac{\tau_{\mathrm{Cr}}}{\mathrm{E}} \times \frac{\ell^{2}}{\mathrm{~h}^{2}}
$$


as the abscissa and ordinate, respectively, the results of some 50 tests plotted along with the theoretical curve are shown in Fig. 3.9.

It can be seen that the theory predicts critical stresses somewhat higher than the experimentally observed values. A more complicated analysis was made by Yoshimura and Niisawa ${ }^{32}$ using the principle of minimum potential energy. But only a special case of this theory, minimizing the potential energy with respect to all the parameters which characterize the wave pattern of buckling (lower bound buckling stress), gives better agreement with the experiments (Fig. 3.10). More recent investigations were made by Ekstrom ${ }^{33}$ and Budiansky. ${ }^{34}$ The results are shown in Fig. 3.11 and Fig. 3.12, respectively. There still remains a discrepancy between theory and test results which may be due to initial imperfections in the material and the effect of endconditions.

\section{B. Inelastic Buckling}

The tor sional buckling strength of a cylinder in the plastic range was investigated by Lee and Ades ${ }^{35}$ and Gerard. ${ }^{16}$ As in the case of an axially compressed cylinder, Gerard established the following plasticity reduction factors for a cylinder under torsion.

For moderate length,

$$
\begin{aligned}
& 50 \frac{\mathrm{h}}{\mathrm{R}}<\left(\frac{\ell}{\mathrm{R}}\right)^{2}<10 \frac{\mathrm{R}}{\mathrm{h}} \\
& \eta_{\mathrm{S}}=\left(\frac{1-\nu_{\mathrm{e}}^{2}}{1-\nu^{2}}\right)^{5 / 8} \times \frac{\mathrm{E}_{\mathrm{S}}}{\mathrm{E}}
\end{aligned}
$$

For long cylinders,

$$
\begin{aligned}
& \left(\frac{\ell}{\mathrm{R}}\right)^{2}>10 \frac{\mathrm{h}}{\mathrm{R}} \\
& \eta_{\mathrm{S}}=\left(\frac{1-\nu_{\mathrm{e}}^{2}}{1-\nu^{2}}\right)^{3 / 4} \times \frac{\mathrm{E}_{\mathrm{S}}}{\mathrm{E}}
\end{aligned}
$$




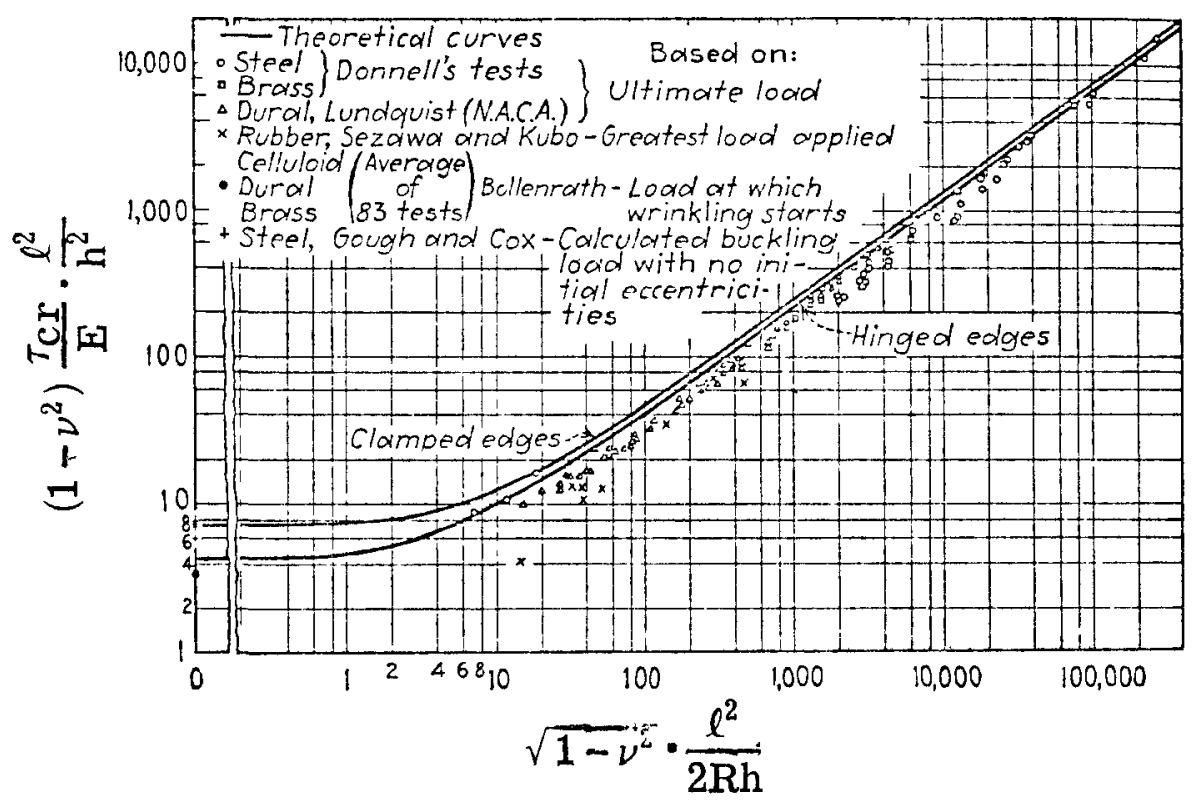

Fig. 3.9-Comparison of Theoretical Solutions and Experiments 


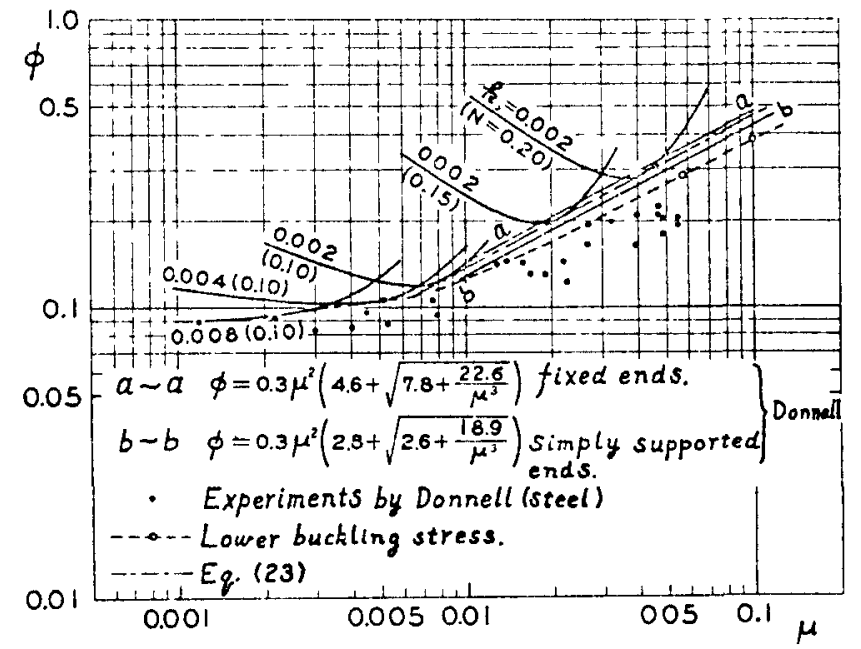

Fig. 3.10 - Upper and Lower Torsional Buckling Stress $\phi=\tau /(\mathrm{E} \vee \eta)$ against $\mu=\pi(\mathrm{a} / \ell) \sqrt[4]{\eta}$ Compared with Experimental Results 


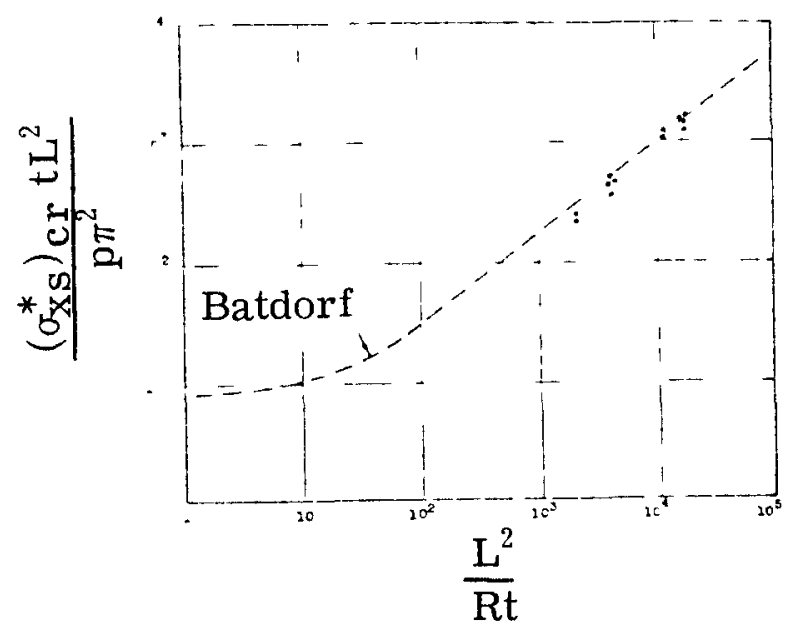

Fig. 3.11 - Buckling Loads for Cylinders under Torsion Alone 


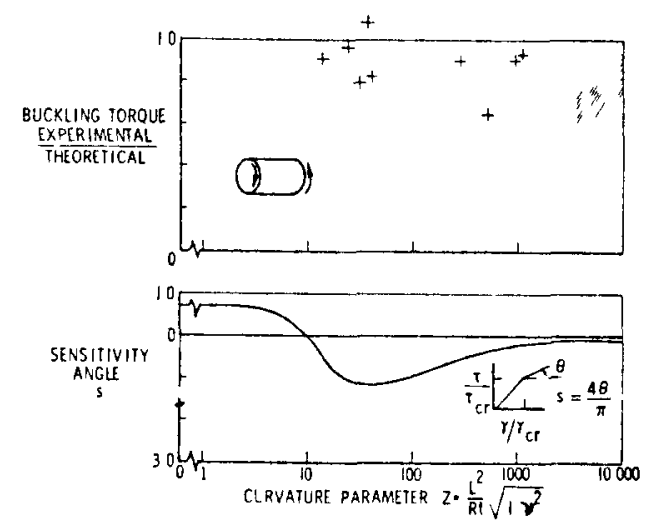

Fig. 3.12 - Comparison of Experiment and Theory for the Buckling of Cylindrical Shells in Torsion and Corresponding Imperfection Sensitivity Angle 
where $\mathrm{E}=$ modulus of elasticity

$\mathrm{E}_{\mathrm{S}}=$ secant modulus

$\nu=$ Poisson's ratio

$\nu_{\mathrm{e}}=$ elastic value of Poisson's ratio

$\mathrm{R}=$ mean radius

$\mathrm{h}=$ wall thickness

$\ell=$ length of cylinder.

The buckling stress in the inelastic range is then given by

$\sigma_{\mathrm{cr}}=\eta_{\mathrm{S}} \times \sigma_{\mathrm{e}}$

where $\sigma_{\mathrm{e}}=$ elastic buckling stress.

Lee and Ades developed an energy solution for finite long cylinders using simple deformation theory for the plastic stress-strain relationship and a more exact solution for an infinite long cylinder based on the same theory. A comparison between theory and experiments is shown in Fig. 3.13 and Table 3.1.

C. Creep Buckling

An analysis method for creep buckling of tubes in torsion was worked out by Finnie. ${ }^{36}$ His conclusion is that the critical shear strain at which torsional buckling should occur is independent of stress and is given by

$$
\gamma_{\mathrm{cr}}=2.24 \frac{\left(1-\mu_{\mathrm{e}}\right)^{3 / 4}}{(1-\mu)^{3 / 4}}\left(\frac{\mathrm{h}}{\mathrm{R}}\right)^{5 / 4}\left(\frac{\mathrm{R}}{\mathrm{h}}\right)^{1 / 2}
$$

The time at which the critical strain is reached, however, depends on the stress and material properties.

\subsubsection{Cylinder under Torsion and External Pressure - Elastic Buckling}

The effect of external lateral or hydrostatic pressure on the buckling resistance of a cylinder loaded in torsion has been considered in two papers. Suer and Harris ${ }^{37}$ and Eckstrom ${ }^{33}$ both present an interaction curve which, in general, follows the parabola 


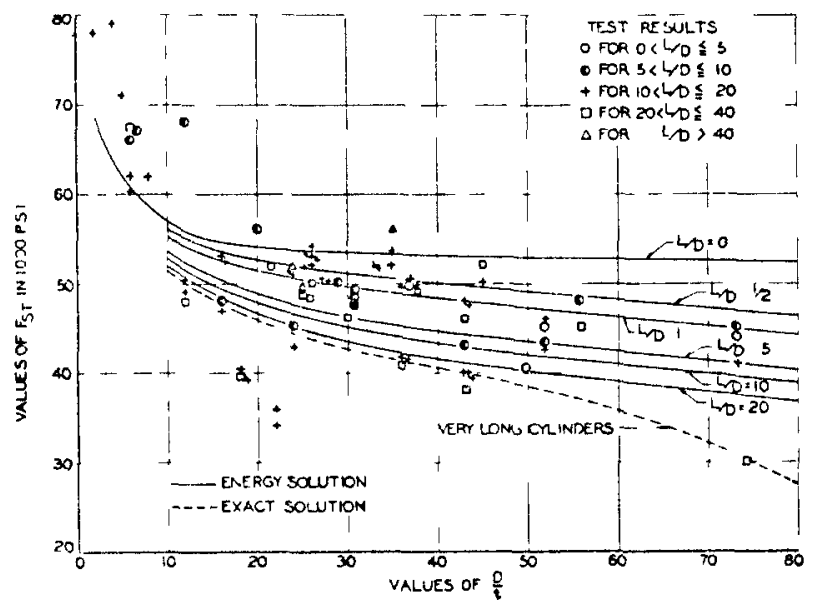

Fig. 3.13 - Comparison of Theory with Experimental Results - Steel Cylinders

$$
\begin{aligned}
\mathbf{F}_{\text {St }} & =\text { torsional modulus of rupture } \\
& =\left(M_{t}\right)_{c r}\left(D / 2 I_{0}\right)
\end{aligned}
$$


TABLE 3.1 - COMPARISON OF THEORY WITH EXPERIMENTAL RESULTS - ALUMINUM-ALLOY CYLINDERS

\begin{tabular}{|c|c|c|c|c|c|c|c|}
\hline Specinen & $D / t$ & $L / D$ & $\begin{array}{c}\Gamma_{\mathrm{n} 7}, \\
\text { psi }\end{array}$ & $\begin{array}{c}\left(\tau_{r r}\right)_{r r m} \\
\text { pSt }\end{array}$ & $\left(\tau_{e r}\right)_{n, 1} p^{-i}$ & $\left(\tau_{r r}\right)_{1} /\left(\tau_{r \tau}\right)_{0}$ & $\left(\tau_{c r}\right)_{r r r} /\left(\tau_{r r}\right)_{0}$ \\
\hline 1 & 9 & 641 & 73.0 .01 & 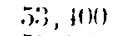 & 54,810 & () 7991 & (i) 852 \\
\hline 2 & 1.51 & 694 & $73,0,30$ & 50,00101 & 50,000 & () 0918.5 & 0982 \\
\hline 3 & 200 & 721 & 73,0150 & $43,6(10)$ & 18,2011 & 069078 & () $90 \mathrm{t}$ \\
\hline 4 & 201 & 655 & 73.0 .01 & 41,80101 & $48,1(11)$ & $0 \leqq 1 \% 9$ & 0032 \\
\hline 5 & $2+9$ & 660 & $73,0.01)$ & 41,900 & $46,4(1)$ & () 9971 & (1) (x)t \\
\hline 6 & 301 & 678 & $73,1) .01$ & $11,7(10)$ & 41,401 & 0 engcii & 1) \\
\hline 7 & 402 & 691 & 73.0 .01 & $38,(610)$ & $10, \pi(3)$ & (1) 91.32 & $019 \%$ \\
\hline 8 & 480 & 698 & 73.0 .51 & $30.2(n)$ & 37.3001 & (1) 98487 & () 97 \\
\hline 9 & $57+$ & 703 & $73,051)$ & $3.3,1(10)$ & $33,7(11)$ & () $18: 2$ & בים \\
\hline 10 & $80) 6$ & 709 & $73.0 \%$ & $20,600)$ & $23,8(1)$ & (1) $0(1,8)$ & $0860 \mathrm{i}$ \\
\hline 11 & 806 & 570 & $4(1,5)$ & $19,1(1)$ & 21,3110 & 0) & 0) 8917 \\
\hline 12 & 598 & 570 & $38,0(1)$ & 18,601 & 22, or & (1) 013,35 & 082.3 \\
\hline 13 & .588 & 170 & $38,(1010)$ & $17,+100$ & $10,8(10)$ & $0 \leq 1,8,3,3$ & 0878 \\
\hline 14 & 394 & 570 & 38,500 & $22,7(1)$ & 25,100 & 0 (1) & 091 \\
\hline 1.5 & 394 & 1711 & $38,500)$ & 22,300 & 22,810 & o) (1:13:3 & 0.978 \\
\hline 16 & $39+$ & 276 & $38,50)$ & 22,0111 & $21,6 f m$ & 0) 90116 & 1 ils \\
\hline 17 & 198 & 571 & 39,800 & 25,4101 & 29,01000 & (1) $97 \times 3$ & 0876 \\
\hline 18 & 198 & 171 & 39,800 & $2 \pi, 100$ & 27,0100 & () 91974 & (1) 929 \\
\hline 10 & 198 & 277 & 39,800 & $2.5,900$ & 26.200 & (1) ous & 1) 848 \\
\hline 20 & 100 & $17 i$ & 39,700 & 28,600 & $30,5 \cap 0$ & (1) mas & 0937 \\
\hline 21 & 806 & $11 \%$ & 40,700 & 15,400 & 17,600 & (1) 9713 & n) 8 \\
\hline 22 & 606 & 115 & $40,000)$ & 20,200 & 21,200 & (1) 1887. & 0019 \\
\hline $2: 3$ & 404 & 115 & 41,500 & 23,900 & $24,810)$ & (1) $99+1$ & of 0,3 \\
\hline \multirow[t]{2}{*}{24} & 20) 1 & 115 & 38,600 & 24,500 & 27,201 & (1) 917! & 0901 \\
\hline & & & & & & & ve $(10,30)$ \\
\hline
\end{tabular}




$$
\mathrm{R}_{\mathrm{S}}^{2}+\mathrm{R}_{\mathrm{p}}=1
$$

where

$$
\begin{aligned}
& \mathrm{R}_{\mathrm{S}}=\frac{\text { Critical torque under combined loading }}{\text { Critical torque under tor sion alone }} \\
& \mathrm{R}_{\mathrm{p}}=\frac{\text { Critical external pressure under combined loading }}{\text { Critical external pressure for pressure alone }}
\end{aligned}
$$

The theoretical analysis is based on Donnell's eighth order differential equation solved by Galerkin's method to determine the buckling coefficients. The resulting theoretical interaction curve is in fairly good agreement with experimental results as shown in Figs. 3.14 and 3.15.

\subsubsection{Cylinder under Torsion and Internal Pressure - \\ Elastic Buckling}

The effect of internal pressure on the buckling resistance of a cylinder loaded in torsion was discussed by Crate et al. ${ }^{38}$ and Hopkins and Brown. ${ }^{39}$ The theoretical analysis uses the same basis and the same method of solution as in the case of external pressure. The interaction curve also follows the parabola

$$
R_{S}^{2}+R_{p}=1
$$

where

$$
\begin{aligned}
& \mathrm{R}_{\mathrm{S}}=\frac{\text { Critical torque under combined load }}{\text { Critical torque under torsion alone }} \\
& \mathrm{R}_{\mathrm{p}}=\frac{\text { Critical internal pressure under combined load }}{\text { Critical internal pressure for pressure alone }}
\end{aligned}
$$

The effect of the internal pressure on the torsional buckling resistance is shown in Fig. 3.16 along with the theoretical curve. 


\section{THEORETICAL}
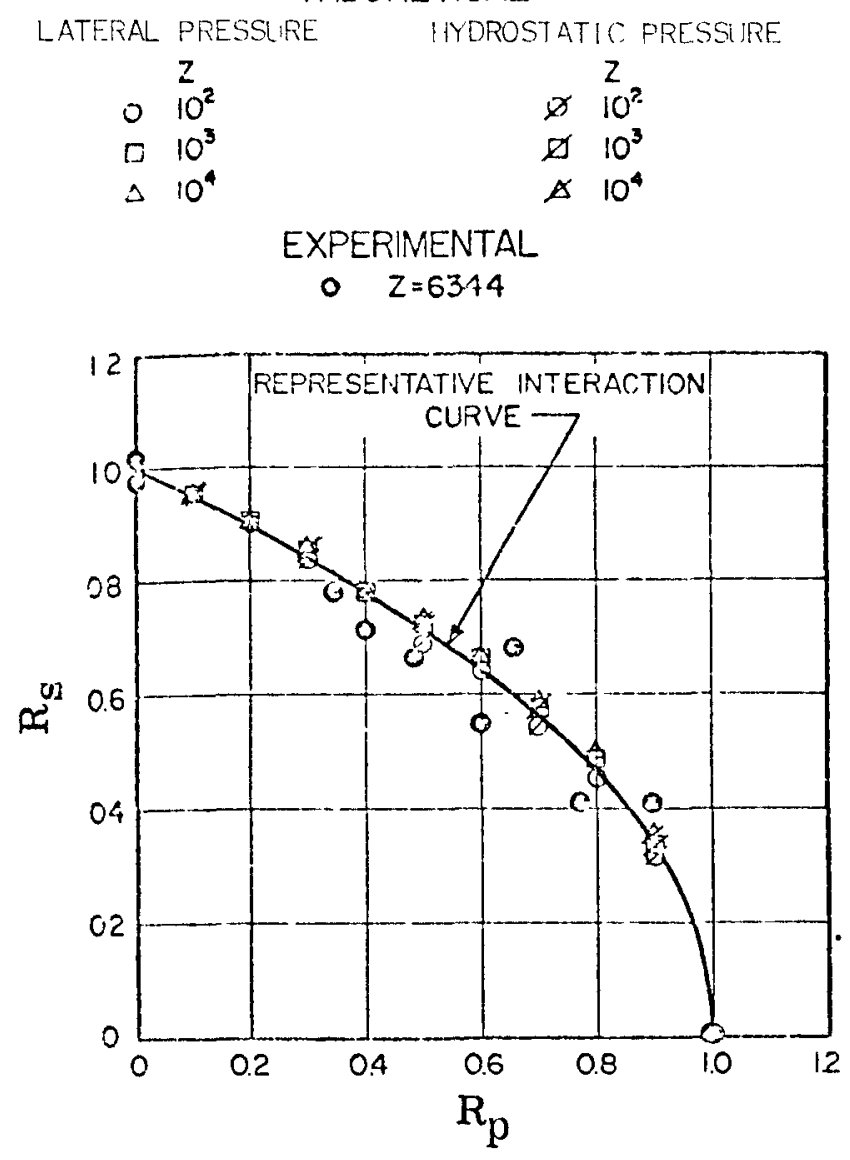

Fig. 3.14 - Interaction Curve for Cylinders under Combined Torsion and External Lateral or Hydrostatic Pressure

$$
\mathrm{Z}=\frac{\mathrm{L}^{2}}{\mathrm{Rh}} \sqrt{1-\nu^{2}}
$$



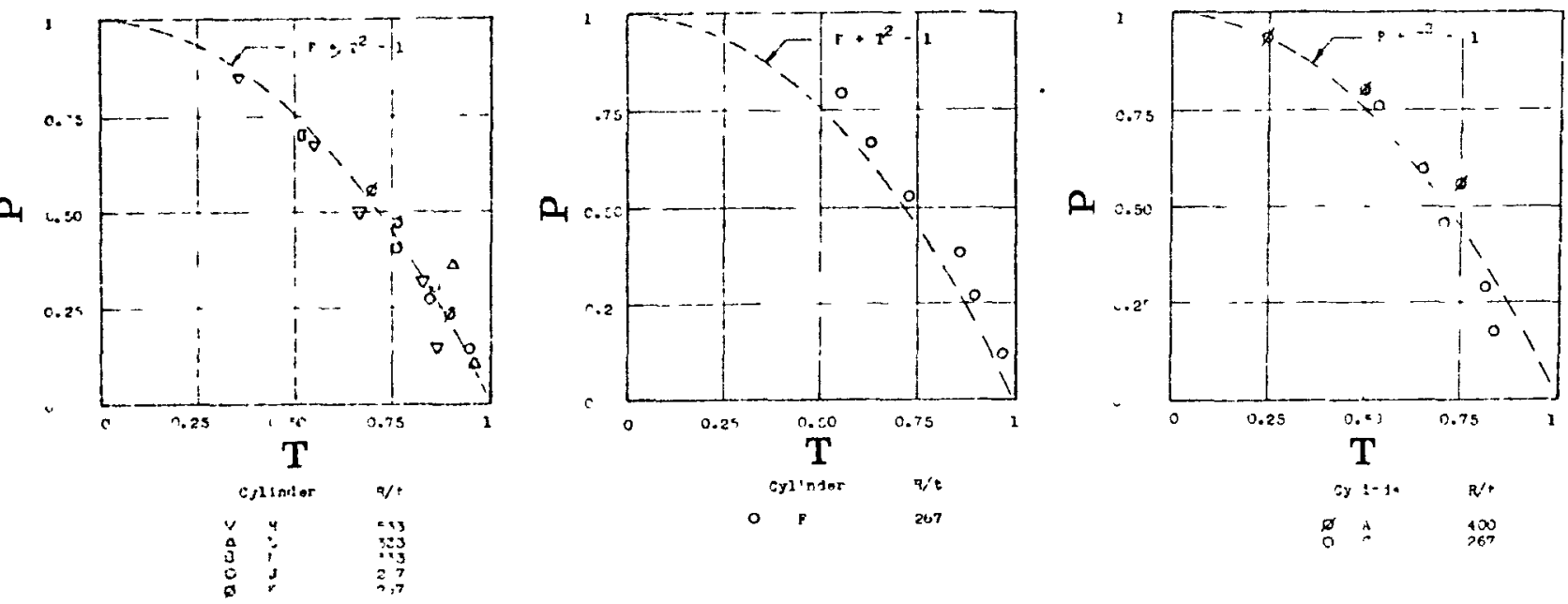

$\mathrm{L}^{2} / \mathrm{Rh}=4000$

$\mathrm{L}^{2} / \mathrm{Rh}=12,000$

$\mathrm{L}^{2} / \mathrm{Rh}=17,500$

Fig. 3.15 - Buckling Loads for Cylinders under Combined Torsion and Hydrostatic Pressure 

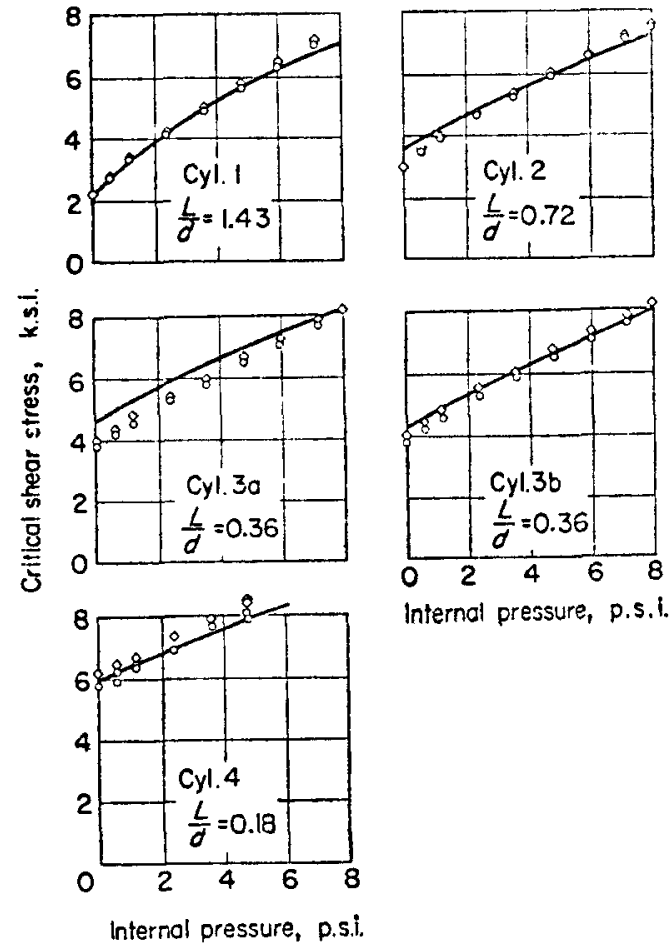

Fig. 3.16 - Effect of Internal Pressure on Torsion Buckling Stress of Cylinders. (For all the cylinders $\mathrm{h}=0.0335$ in. and $\mathrm{d}=30 \mathrm{in}$. For cylinders 1,2 , and $3 \mathrm{a}$ the rings are on the inside and outside - clamped edge conditions are assumed in the calculation of theoretical results. For cylinders $3 \mathrm{~b}$ and 4 , the rings are on the inside only - simply supported edge conditions are assumed in the calculation of theoretical results.) 


\subsection{CYLINDER UNDER BENDING}

The buckling behavior of a cylinder under bending is very similar to the buckling behavior of a cylinder under compression, in that the few theoretical investigations do not agree in their solutions, and, as in the case of axial compression, there is poor agreement between theory and experiment.

\subsubsection{Cylinder under Bending Only}

A. Elastic Buckling

The elastic buckling behavior of thin-walled cylinder under bending was theoretically investigated by Flügge. ${ }^{23}$ He found that the theoretical bending stress is 1.3 times theoretical stress for a cylinder in axial compression. This analysis was commonly accepted. A more recent analysis method of this problem was presented by Seide and Weingarten. ${ }^{40}$ The results of their investigations have shown that for moderately long and long cylinders with $R / h$ ratios $>100$, the critical bending stress is equal to the critical compressive stress. For short cylinders and low $\mathrm{R} / \mathrm{h}$ ratios, the theory shows higher critical buckling stresses for bending than for compression. The authors believe that the difference is due to the fact that end effects have been neglected. There is poor agreement between the theories and experimental results. A large deflection theory might show better agreement with the experiment, as in the case of axial compression, but such an analysis has not yet been accomplished.

An extensive experimental investigation on the critical buckling stress for cylinders in bending was done by Suer et al. ${ }^{41}$ The results are shown in Fig. 3.17 along with experimental results of other investigators. The best results were evaluated by the authors with statistical methods in the same way as with the test results for axially compressed cylinders.

\section{B. Inelastic Buckling}

An analysis method for the bending strength of tubing in the plastic range was developed by Ades in Reference 5. He uses the principle of least work to determine the shape of the cross section as a function of its longitudinal curvature and then the bending moment carried by the 


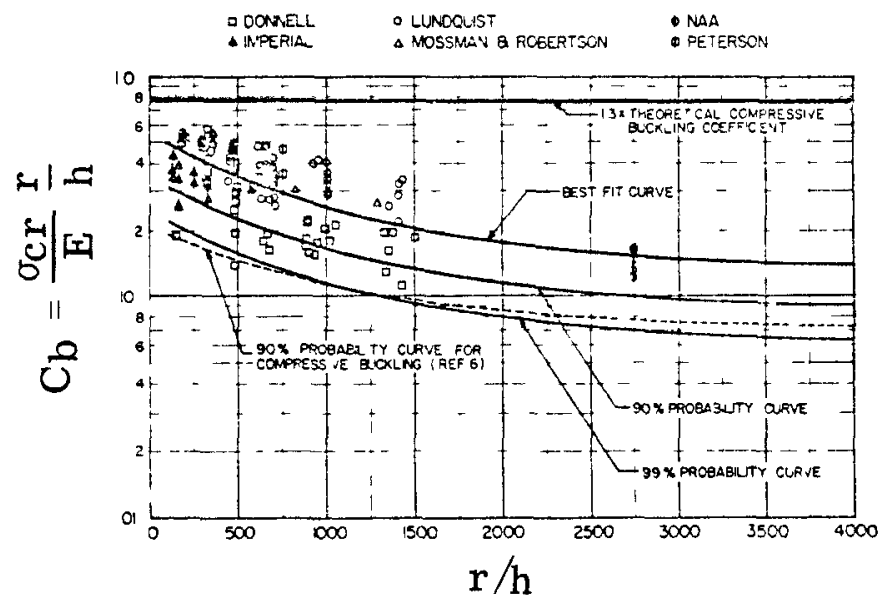

Fig. 3.17 - Unpressurized Bending Buckling Stress Coefficients as a Function of $\mathrm{r} / \mathrm{h}$ (Semilogarithmic Grid) 
tube related to a certain shape. The analysis method was programmed for a high-capacity digital computer because numerical integration and iteration processes are needed to determine the maximum moment. A comparison was made of the bending modulus of rupture as a function of $\mathrm{R} / \mathrm{h}$ ratio predicted by theory and determined in experiment. The comparison is shown in Fig. 3.18. To be conservative, the theory used the conventional stress-strain curve instead of the so-called true stressstrain curve.

C. Creep Buckling

The creep-buckling behavior of a cylinder under bending was tested by Samuelson. ${ }^{42}$ He found that for some stress levels, the cylinders subjected to bending had a substantially longer lifetime than those subjected to axial compression. The results of his tests are shown in Fig. 3.19.

\subsubsection{Cylinder under Bending Including Internal Pressure - Elastic Buckling}

The critical buckling stress of a cylinder under bending is increased by internal pressure. This was proved by Suer et al. ${ }^{41}$ They conducted two series of tests. In one series, the longitudinal component of the internal pressure was balanced by an axial compressive load before the bending moment was applied, while, in the second series, the longitudinal component of the internal pressure was not balanced. The increase in the critical buckling stress for both series is shown in Fig. 3.20. A theoretical analysis method was developed by Weingarten. ${ }^{43}$ This theory is an extension of the analysis method for pure bending given by the same author.

\subsection{CYLINDER UNDER INTERNAL PRESSURE}

The mechanical stress in a thin-wall cylinder subject to internal pressure is

$$
\sigma_{\theta}=\frac{\operatorname{Pr}}{\mathrm{h}}
$$

in the circumferential direction, and 


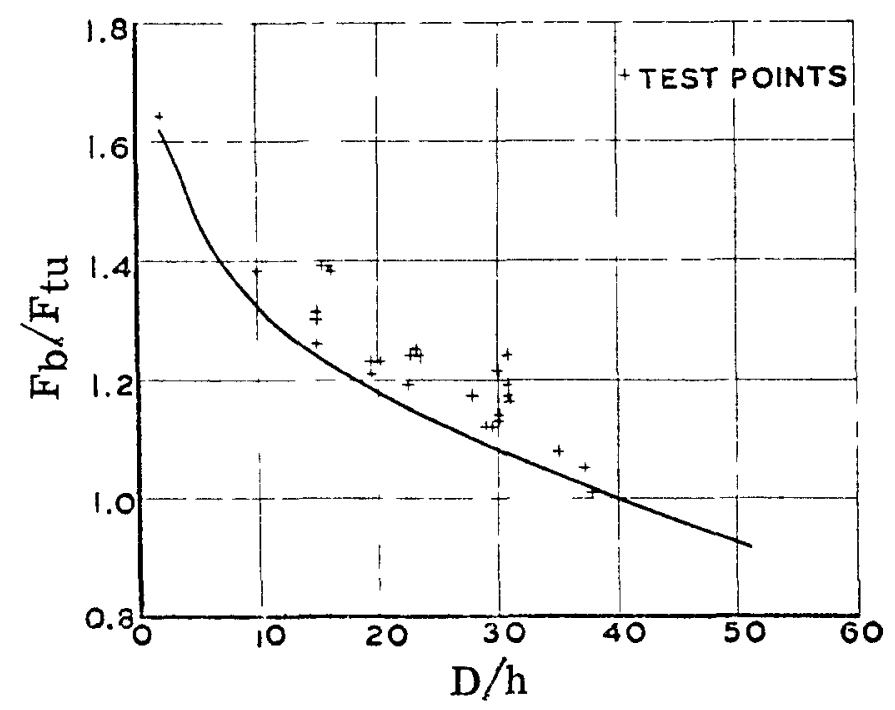

Fig. 3.18 - Computed and Experimental Bending Modulus of Rupture Data - 260,000 U.T.S. Round Tubing

$F_{b}=$ bending modulus of rupture

$F_{\text {tu }}{ }^{`}=$ ultimate tensile strength 


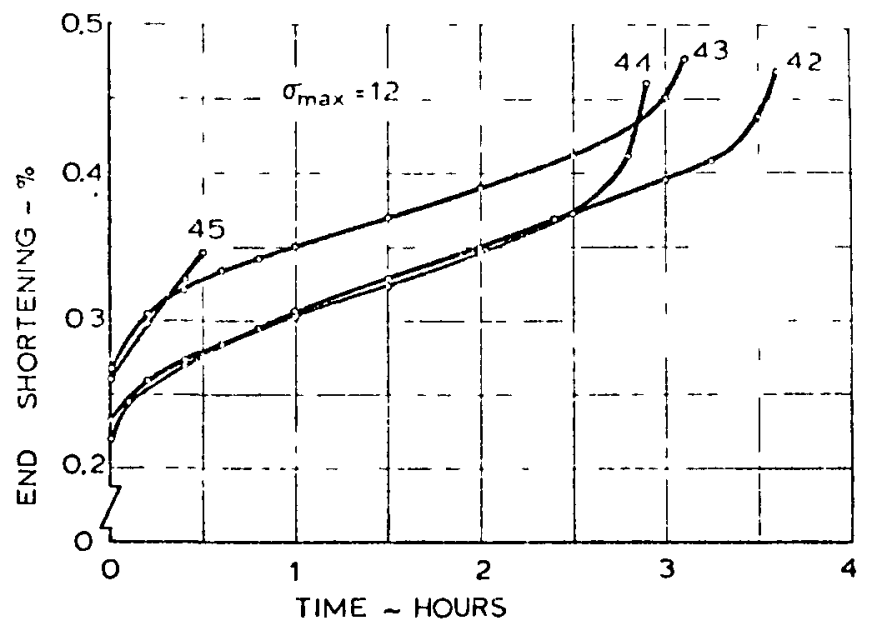

Fig. 3.19-Creep Buckling Curves for Four Cylinders under Bending. The diagram shows the shortening of the shell meridian at the point of maximum compressive stress. 


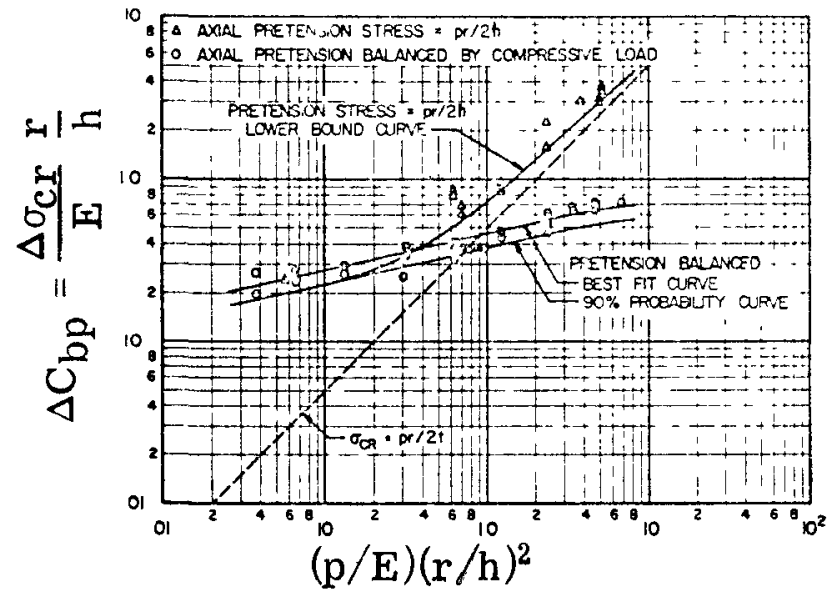

Fig. 3.20 - Increase in Bending Buckling Stress Coefficients Due to Internal Pressure 


$$
\sigma_{\mathrm{X}}=\frac{\operatorname{Pr}}{2 \mathrm{~h}}
$$

in the axial direction,

where $\mathrm{P}=$ internal pressure

$\mathbf{r}=$ mean radius

$\mathrm{h}=$ wall thickness.

The effect of the internal pressure combined with other types of loading (axial compression, torsional and bending moment) is described in the previous sections.

Analysis methods to determine the plastic instability of a cylinder due to internal pressure is given by Bert et al. in References 29 and 30, and Felgar in Reference 44.

\subsection{CYLINDER UNDER EXTERNAL PRESSURE}

Considering the design and operating conditions for the LMFBR piping system, the external pressure itself is not very high, but in combination with bending and torsional moments and axial loading, external pressure reduces the critical buckling stress as described in the previous sections.

\subsubsection{Cylinder under Lateral External Pressure}

\section{A. Elastic Buckling}

For an infinitely long cylinder under lateral external pressure, the classical theory gives the critical buckling pressure as

$$
\mathrm{P}_{\mathrm{cr}}=\frac{\mathrm{E}}{4\left(1-\nu^{2}\right)}\left(\frac{\mathrm{h}}{\mathrm{R}}\right)^{3}
$$

A more accurate theory, including end effects, was developed by Batdorf ${ }^{45}$ using Donnell's equations. He represented his results in two parameters: a pressure parameter,

$$
C_{p}=\frac{P R l^{2}}{\mathrm{D} \pi^{2}}
$$


and a geometric parameter

$$
\mathrm{Z}_{\mathrm{h}}=\left(\frac{\mathrm{L}}{\mathrm{R}}\right)^{2} \frac{\mathrm{R}}{\mathrm{h}} \sqrt{1-\nu^{2}}
$$

For experimental tests without initial imperfections, the theory is in good agreement with the test results (Fig. 3.21) even for low $R / t$ ratios where one would expect that the buckling occurs in the inelastic region. The reason for the better agreement in the case of lateral pressure than in the case of axial compression is the difference in the post-buckling behavior. For a cylinder under lateral pressure, there is no stable equilibrium at a lower load in the post-buckling region as there is for a cylinder under axial compression.

A theory including initial imperfections (out of roundness) was developed by Donnell. ${ }^{46}$ He added to a pressure and length parameter an initial displacement parameter.

The pressure parameter is given as

$$
\overline{\mathrm{p}}=\frac{\mathrm{R}^{3 / 2} \mathrm{Lp}}{\mathrm{h}^{5 / 2} \mathrm{E}},
$$

the length parameter as

$$
\widetilde{\mathrm{L}}=\frac{\mathrm{L}}{\sqrt{\mathrm{Rh}}},
$$

and the initial displacement parameter as

$$
\frac{\mathrm{uR}}{\mathrm{h}}=\frac{\pi^{2} \mathrm{aRh}}{\sqrt{\mathrm{l}_{\mathrm{X}} \ell_{\mathrm{S}}}}
$$

where $u$ is recommended to be in the order of 0.0001 to 0.0008 , and where $\mathrm{a} h=$ amplitude of the initial deformation

$\ell_{\mathrm{X}}, \ell_{\mathrm{S}}=$ half-wave lengths of primary buckling waves in axial and circumferential directions, respectively,

and a parameter, $\mathrm{V}$, representing the change in volume is given by

$$
\mathrm{V}=\frac{\text { volume decrease }}{(\mathrm{Rh})^{3 / 2}}
$$




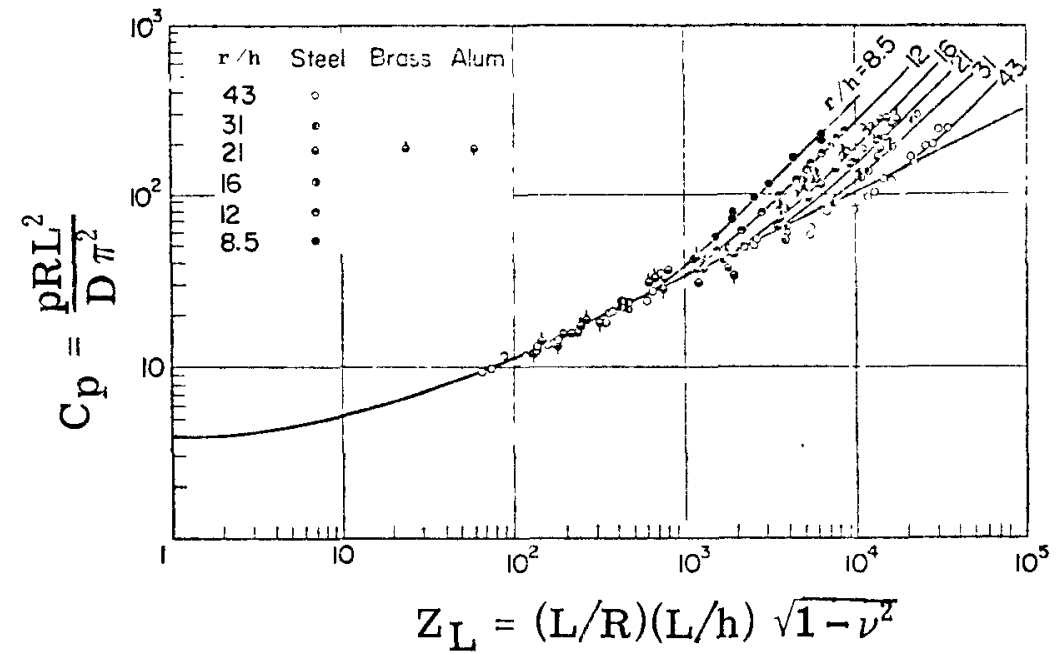

Fig. 3.21 - Buckling Pressure of Cylinders with Small R/h Ratio $(8.5<\mathrm{R} / \mathrm{h}<43)$ 
B. Inelastic Buckling

An analysis method for inelastic buckling was presented by Corum in Reference 4. The basic idea of his theory is that buckling occurs when the equilibrium between the applied bending moment and the restoring moment becomes an unstable one. This method was expanded by United Nuclear Corporation to predict the buckling load as a function of initial ovality. The corresponding computer program COLLAPSE developed by United Nuclear is described in Section 6. The computer code was checked against experimental results and shows good agreement with a safety margin of about 10 to $20 \%$ (see Table 3.2 ).

\section{Creep Buckling}

For time-dependent deformation creep buckling, different methods are available to determine the critical time. The critical time is the time at which an ovality is reached which would cause instantaneous buckling. All methods use the equilibrium equations and strain-displacement relations for an elastic body. The differences in the mathematical formulation of a creep problem are the stress-strain relations, which are time dependent.

The United Nuclear Corporation program CRE-BUCK which predicts the increase in radial deflection due to creep is also described in Section 6. The method of the program is a biaxial analysis. The radial deflection is represented by a Fourier cosine series. The change in the creep strain is computed by numerical integration over many small time intervals, assuming the stress constant during the interval and increasing as a step function at the end of the interval. To obtain the triaxial creep rates from uniaxial creep data, the von Mises flow rule or the Tresca flow rule can be used. The program was checked against a limited amount of experimental data and shows reasonably conservative results.

Other methods are given by Sanders, ${ }^{47}$ Hoff, ${ }^{48}$ Ellington, ${ }^{49}$ and Glückler et al. ${ }^{50}$ The work by Glückler is based on Hoff's and Ellington's theories. The method predicts the increase of the ovality of a tube under external pressure due to creep using the creep law of NuttingScott, Blair: 


$$
\dot{\epsilon}=\mathrm{Km} \mathrm{t}^{\mathrm{m}-1} \sigma^{\mathrm{n}}
$$

where $\mathrm{m}=$ creep parameter for primary creep

$\mathrm{n}, \mathrm{K}=$ creep parameters for secondary creep

$\mathrm{t}=$ time

$\sigma=$ stress.

The theory shows very good agreement with experimental results but this agreement probably was reached by using a variation of the creep parameter to get the best fit to the experimental results. The creep parameters were derived from a theoretical basis instead of by fitting experimental curves. 
TABLE 3.2 - COLLAPSE PRESSURES FOR THIN-WALLED TUBES - EXPERIMENTAL DATA

From Reference 4

\begin{tabular}{|c|c|c|c|c|c|c|c|c|}
\hline Number & Material & Temperature & $\mathrm{OD}$, in. & $\begin{array}{l}\text { Thickness, } \\
\text { in. }\end{array}$ & $\begin{array}{l}\text { Ovality, } \\
\text { in. }\end{array}$ & $\begin{array}{l}\text { of Collapse } \\
\text { Pressure, psi }\end{array}$ & $\begin{array}{l}\text { Collapse, } \\
\text { psi }\end{array}$ & Remarks* \\
\hline $\mathrm{RD} 5$ & Type 304 SS & $\mathrm{RT}$ & 8.017 & 0.257 & 0.036 & $1275+7.5 \%$ & 1185 & $\begin{array}{l}\text { Experiment not correct, an additional unmeasured } \\
\text { ovality is possible }\end{array}$ \\
\hline $\mathrm{RD} 2$ & Type 304 SS & $1200^{\circ} \mathrm{F}$ & 8.001 & 0.245 & 0.18 & $540-31 \%$ & 780 & $\begin{array}{l}\text { Max. ovality is very localized positive effect for col- } \\
\text { lapse pressure; mean ovality gives a collapse pres- } \\
\text { sure of } 680 \text { psi }\end{array}$ \\
\hline UT 1 & Type 304 SS & $1200^{\circ} \mathrm{F}$ & 4.032 & 0.120 & 0.004 & $600+2 \%$ & 588 & - \\
\hline UT 3 & Type 304 SS & $1200^{\circ} \mathrm{F}$ & 4.005 & 0.119 & 0.013 & $560+3.5 \%$ & 542 & - \\
\hline UT 2 & Type 347 SS & $1200^{\circ} \mathrm{F}$ & 4.018 & 0.120 & 0.011 & $760-21 \%$ & 991 & $\begin{array}{l}\text { No uniform temp distribution from } 920 \text { to } 1200^{\circ} \mathrm{F} \text {. Pre- } \\
\text { diction used the stress-strain curve at } 1200^{\circ} \mathrm{F} \text {. }\end{array}$ \\
\hline UT 4 & Type 347 SS & $1200^{\circ} \mathrm{F}$ & 4.01 & 0.126 & 0.003 & $950+5.5 \%$ & 900 & $\longrightarrow$ \\
\hline \multicolumn{9}{|c|}{ UNC Data } \\
\hline $4-241 \mathrm{~A}$ & Zircaloy-4 & $\mathrm{RT}$ & 0.3664 & 0.0229 & 0.0008 & $6200-20.5 \%$ & 7800 & \multirow{6}{*}{$\begin{array}{l}\text { The measured axial stress-strain curves were used in } \\
\text { the predictions }\end{array}$} \\
\hline $4-241 \mathrm{D}$ & Zircaloy-4 & $\mathrm{RT}$ & 0.3664 & 0.0229 & 0.0006 & $6300-23 \%$ & 8200 & \\
\hline $4-241 \mathrm{E}$ & Zircaloy-4 & $\mathrm{RT}$ & 0.3664 & 0.0229 & 0.0005 & $6300-23 \%$ & 8200 & \\
\hline $4-241 \mathrm{~F}$ & Zircaloy-4 & $\mathrm{RT}$ & 0.3664 & 0.0229 & 0.0003 & $6360-22 \%$ & 8200 & \\
\hline $4-241 \mathrm{C}$ & Zircaloy-4 & $\mathrm{RT}$ & 0.3664 & 0.0229 & 0.0012 & $6120-23 \%$ & 8000 & \\
\hline $3-241 \mathrm{E}$ & Zircaloy-4 & $\mathrm{RT}$ & 0.3664 & 0.0229 & 0.0005 & $6300-17 \%$ & 7600 & \\
\hline
\end{tabular}


TABLE $3.2-($ CONTINUED)

\begin{tabular}{|c|c|c|c|c|c|c|c|c|c|}
\hline \multirow[b]{2}{*}{ Number } & \multirow[b]{2}{*}{ Material } & \multirow[b]{2}{*}{ Temperature } & \multicolumn{4}{|c|}{ From Reference 118} & \multirow[b]{2}{*}{$\begin{array}{c}\text { Actual } \\
\text { Collapse, } \\
\text { psi } \\
\end{array}$} & & \multirow[b]{2}{*}{ Remarks } \\
\hline & & & $\underline{O D, \text { in. }}$ & $\begin{array}{l}\text { Wall } \\
\text { Thickness, } \\
\text { in. } \\
\end{array}$ & $\begin{array}{l}\text { Maximum } \\
\text { Ovality, } \\
\text { in. } \\
\end{array}$ & $\begin{array}{l}\text { UNC Prediction } \\
\text { of Collapse } \\
\text { Pressure, psi } \\
\end{array}$ & & & \\
\hline $1 \mathrm{~A}-4$ & $\begin{array}{l}\text { Zirc-4 ASTM } 11 \\
>70 \% \mathrm{cw}\end{array}$ & $700^{\circ} \mathrm{F}$ & 0.280 & 0.018 & Unknown & $4910-12.5 \%$ & 5600 & & \\
\hline $2 A-6$ & Zirc-4 ASTM 9 & $700^{\circ} \mathrm{F}$ & 0.280 & 0.018 & Unknown & $5479-11.5 \%$ & 6080 & $\begin{array}{l}\text { The axia } \\
\text { were us }\end{array}$ & $\begin{array}{l}\text { stress-strain data from the report } \\
\text { sed in the predictions }\end{array}$ \\
\hline $3 D-1$ & Annealed & $700^{\circ} \mathrm{F}$ & 0.280 & 0.018 & Unknown & $2842-25 \%$ & 3800 & - & \\
\hline $4 \mathrm{~B}-1$ & $15 \% \mathrm{cw}$ beta & $700^{\circ} \mathrm{F}$ & 0.280 & 0.018 & Unknown & $5540-10.5 \%$ & 6200 & - & \\
\hline
\end{tabular}


4. ANALYSIS METHODS FOR ELBOWS, LATERALS, TEE'S, LOCAL PADS FOR HANGERS, SUPPORTS, ETC.

\subsection{ANALYSIS METHODS FOR ELBOWS AND RETURNS}

The available analysis methods are able to calculate the increase in the flexibility which is caused by a distortion of the cross section. The distortion of the cross section certainly will have an effect on the buckling resistance of the tube. The deflection from the circular cross section is given by the flexibility factor $\mathrm{K}$, where $\mathrm{K}$ is defined as:

$$
\begin{aligned}
& \mathrm{K}=\frac{\text { (Measured deflection) }}{\text { (Calculated deflection of an identically loaded bar having }}= \\
& =\frac{\delta \text { (meas.) }}{\left.\frac{2 \mathrm{PR}^{2}}{\mathrm{EI}} \cdot \frac{\pi \mathrm{R}}{4}+\alpha\right]}
\end{aligned}
$$

The stress intensification which is caused by the distortion of the cross section is expressed by the stress intensification factor, $\beta_{\ell}, \beta_{t}$, and $\beta_{\ell 0}$, where

(Maximum longitudinal stress in outer surface computed

$$
\begin{aligned}
\beta_{\ell} & =\frac{\text { from meas }}{\text { (Calculated }} \\
& \text { having the } \\
& =\frac{\sigma_{\ell}(\max )}{\mathrm{MD} / 2 \mathrm{I}}
\end{aligned}
$$

maximum longitudinal stress in a curved bar the same section modulus and radius of curvature)*

\footnotetext{
*Neglecting shift in neutral axis.
} 


$$
\begin{aligned}
& \beta_{t}= \begin{array}{l}
\text { (Maximum transverse stress in outer surface computed } \\
\text { (Calculated maximum longitudinal stress in a curved bar } \\
\text { having the same section modulus and radius of curvature })^{*}
\end{array} \\
&= \frac{\sigma_{t}(\mathrm{max})}{\mathrm{MD} / 2 \mathrm{I}} \\
& \beta_{\ell 0}= \frac{\text { from measured data) }}{\text { (Calculated maximum longitudinal stress in a curved bar }} \\
&\text { having the same section modulus and radius of curvature })^{*}
\end{aligned}
$$

Test results, shown in Table 4.1, are used to establish empirical expressions for the flexibility factor and the stress intensification factors. The work was done by Vissat and Del Buono in Reference 51.

These empirical expressions are only valid for the tested range of the flexibility characteristics, $\tau$. The flexibility factor is given by

$\mathrm{K}=\frac{1.40}{\tau}$

The stress intensification factors are given by:

$$
\begin{aligned}
& \beta_{\ell}=\frac{1.20}{\tau^{0.67}} \\
& \beta_{t}=\frac{1.07}{\tau^{0.78}} \\
& \beta_{l 0}=\frac{1.12}{\tau^{0.67}}
\end{aligned}
$$

*Neglecting shift in neutral axis. 
4-3

TABLE 4.1 - DISCUSSION OF RESULTS AND CONCLUSIONS - SUMMARY OF TEST RESULTS

\begin{tabular}{|c|c|c|c|c|c|c|c|c|c|c|c|c|c|c|c|}
\hline \multirow{3}{*}{$\begin{array}{l}\text { Nominal } \\
\text { Size, in. }\end{array}$} & \multirow{3}{*}{$\begin{array}{c}\text { Sched. } \\
\text { No. }\end{array}$} & \multirow{3}{*}{$\begin{array}{l}\text { Outside } \\
\text { Diam, } \\
\text { D, in. }\end{array}$} & \multirow{3}{*}{$\begin{array}{c}\text { Wall } \\
\text { Thickness, } \\
\text { t, in. }\end{array}$} & \multirow{3}{*}{$\begin{array}{l}\text { Mean Pipe } \\
\text { Radius, } \\
\text { r, in. }\end{array}$} & \multirow{3}{*}{$\begin{array}{r}\text { Bend } \\
\text { Radius, } \\
\mathrm{R}, \text { in. }\end{array}$} & \multirow{3}{*}{$\begin{array}{l}\alpha= \\
\mathrm{r} / \mathrm{R}\end{array}$} & \multirow{3}{*}{$\begin{array}{c}\alpha^{\prime}= \\
(\text { Nom }) / 2 R\end{array}$} & \multirow{3}{*}{$\begin{array}{c}\lambda= \\
\mathrm{tR} / \mathrm{r}^{2}\end{array}$} & \multicolumn{2}{|c|}{ Flexibility Factor } & \multicolumn{5}{|c|}{ Stress Intensity Factors } \\
\hline & & & & & & & & & \multirow{2}{*}{$\begin{array}{l}\text { Unflanged } \\
\mathrm{K}(1) \\
\end{array}$} & \multirow{2}{*}{$\begin{array}{l}\text { Flanged } \\
\mathrm{K} \\
\end{array}$} & \multicolumn{3}{|c|}{ Unflanged } & \multicolumn{2}{|c|}{ Flanged } \\
\hline & & & & & & & & & & & $\underline{\beta_{\ell}(2)}$ & $\underline{\beta_{t}(3)}$ & $\beta_{\ell}(4)$ & $\beta_{l}$ & $\beta_{t}$ \\
\hline 8 & $\mathrm{LW}$ & 8.340 & 0.150 & 4.095 & 8.0 & 0.512 & $1 / 2$ & 0.0714 & 13.58 & 12.29 & 6.42 & 8.01 & 5.68 & 6.16 & 7.46 \\
\hline 6 & LW & 6.625 & 0.150 & 3.238 & 9.0 & 0.360 & $1 / 3$ & 0.1288 & 11.98 & 11.29 & 5.04 & 6.14 & 4.93 & 5.05 & 6.16 \\
\hline 5 & LW & 5.625 & 0.150 & 2.738 & 7.5 & 0.365 & $1 / 3$ & 0.1500 & 9.44 & 8.77 & 3.90 & 4.98 & 3.59 & 3.92 & 4.80 \\
\hline 8 & 40 & 8.700 & 0.350 & 4.175 & 8.0 & 0.522 & $1 / 2$ & 0.1606 & 7.66 & 7.18 & 4.16 & 4.29 & 4.23 & 4.02 & 4.14 \\
\hline 8 & 80 & 8.600 & 0.500 & 4.050 & 8.0 & 0.506 & $1 / 2$ & 0.2439 & 5.54 & 5.54 & 3.49 & 2.97 & 3.45 & 3.40 & 2.97 \\
\hline 6 & 40 & 6.655 & 0.295 & 3.180 & 9.0 & 0.353 & $1 / 3$ & 0.2626 & 5.46 & 5.13 & 2.90 & 3.01 & 2.85 & 2.91 & 3.03 \\
\hline 5 & 40 & 5.606 & 0.277 & 2.665 & 7.5 & 0.381 & $1 / 3$ & 0.2925 & 5.45 & 5.50 & 2.72 & 2.95 & 2.41 & 2.70 & 2.89 \\
\hline 8 & 120 & 8.562 & 0.748 & 3.907 & 8.0 & 0.488 & $1 / 2$ & 0.3953 & 3.28 & 3.28 & 2.44 & 1.91 & 2.23 & 2.42 & 1.90 \\
\hline 6 & 80 & 6.626 & 0.432 & 3.097 & 9.0 & 0.344 & $1 / 3$ & 0.4074 & 3.53 & 3.50 & 2.09 & 2.14 & 2.05 & 2.09 & 2.18 \\
\hline 5 & 80 & 5.571 & 0.425 & 2.573 & 7.5 & 0.343 & $1 / 3$ & 0.4796 & 2.95 & 2.86 & 1.83 & 1.91 & 1.78 & 1.93 & 2.13 \\
\hline 6 & 120 & 6.625 & 0.562 & 3.032 & 9.0 & 0.337 & $1 / 3$ & 0.5503 & 2.38 & 2.40 & 1.59 & 1.63 & 1.47 & 1.61 & 1.63 \\
\hline 6 & 160 & 6.625 & 0.718 & 2.954 & 9.0 & 0.328 & $1 / 3$ & 0.7404 & 1.92 & 1.77 & 1.57 & 1.56 & 1.37 & 1.58 & 1.57 \\
\hline
\end{tabular}


Similar work was done by von Karman, ${ }^{52}$ Beskin, ${ }^{53}$ Symonds and Pardue, ${ }^{54}$ and Gross and Ford. ${ }^{55}$

Using analysis methods as described above to calculate deflection and stress intensification, one must develop a relationship to find the corresponding buckling load. For some loading conditions the buckling resistance of an elbow or a return is larger than the collapse resistance of the straight tube. This was shown indirectly by Sobel and Flügge ${ }^{56}$ for external pressure. They tested toroidal shells from almost complete torus to $180^{\circ}$ torus. Their results show that the critical buckling pressure for a toroidal shell decreases with increasing $b / r$,

where $b=$ mean radius of the torus

$\mathbf{r}=$ mean radius of the tube.

As $\mathrm{b}$ goes to infinity, the critical buckling pressure should approach that of a straight tube. The same conclusion should be true for a $90^{\circ}$ torus.

For applied bending moments the flexibility analysis shows larger increases in ovality and stress intensification for in-plane bending than for out-of-plane bending.

For both loading conditions, however, buckling should occur in the elbow or return rather than in the straight tube. In order to choose between the several analytical solutions possible, a few tests should be conducted. Every possible analytical solution should be verified by a few tests. The tests should be designed to answer these questions:

1. Does the buckling occur in the elastic or inelastic range?

2. What are the stresses and strains that occur during loading up to the point of buckling?

With regard to the mathematical complexity of the buckling analysis for axisymmetric geometrical considerations, it seems impossible to derive a proper theoretical analysis method for nonaxisymmetric geometrical considerations in the time scheduled for preparation of the design guide. Therefore, a simple approximation using linear shell theory is the only feasible way.

The following analysis method, which is only briefly described, may be a possible way to give an approximate solution for the buckling load of an elbow or return subjected to in-plane bending. 


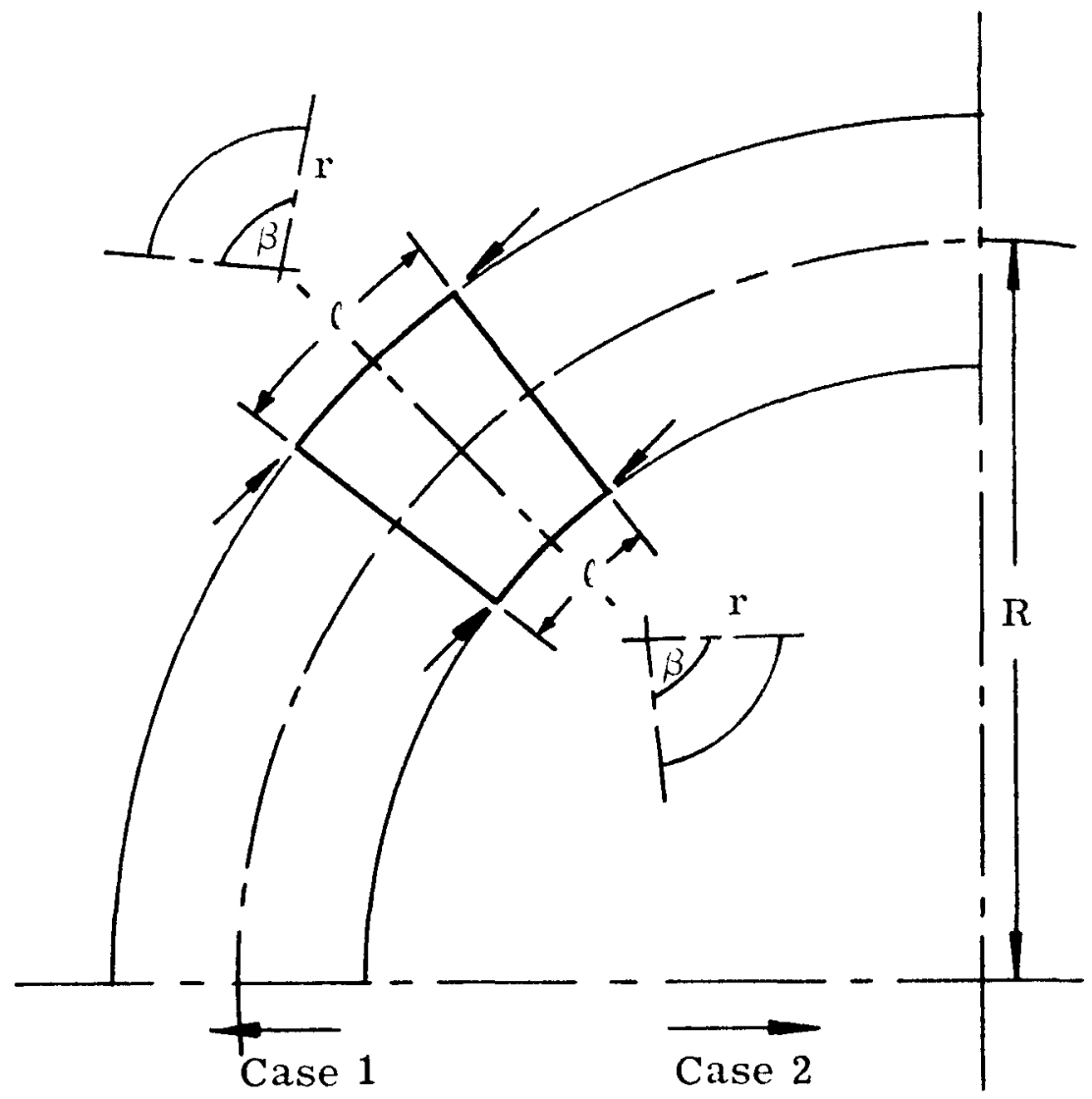

The general assumption is that the critical location for buckling is in the compression range.

\section{Analysis Method}

The applied bending moment in Case 1 (Case 2) would cause compression stresses in the outer (inner) surface of the elbow. The stress can be calculated using the stress intensification factor which is given by the flexibility analysis. Consider a curved panel with the angle $\beta$ and length $\ell$ out of the tube wall; this panel is assumed to represent the critical section of the elbow. For elastic conditions, the load can be calculated which would cause the same stress in the panel. This load or the stress can be checked against the critical buckling load stress, using Timoshenko's ${ }^{27}$ equations for the curved panel. This approach should be limited to large bend elbows and returns, with the radius 
of the bend greater than 10 times the radius of the tube. For an elbow or return with a small bend radius, a small rectangular plate, instead of a curved panel, could be used to represent the critical section.

Another method given by S. Levy in Reference 57 is worth investigating. He developed equations for the axisymmetric distortion of short cylindrical shells including the effect of shear in the walls.

For inelastic buckling a similar model could be used to give an approximate solution.

The development work which is needed to establish proper design methods for elbows and returns is described in Section 5.

\subsection{ANALYSIS METHODS FOR WELDED TUBULAR CONNECTIONS}

Local instability in the region of tubular connections, such as $\mathrm{Y}-, \mathrm{K}-$, and $\mathrm{T}$-joints, is an unexplored field. As in the case of elbows and returns, the problem is so complex that any analytical method should be based on experimental observations. The presence of high temperatures, which cause creep, makes the deformation behavior even more unpredictable. Experimental results, from tension tests to check failure modes, show that the possibility for buckling is larger in case of tubular connections of same size tubes than in the case of a connection with a small size tube.

Stress analysis methods for tubular joints are given by Beale and Toprac, ${ }^{58}$ Hansberry and Jones, ${ }^{59}$ and Greste and Clough. ${ }^{60}$ The latter used the finite element method and got reasonable agreement with experimental measurements. Additional experiments to this analysis are now under way at Oak Ridge National Laboratory. Instead of developing a buckling analysis method for tubular intersections, which would require an extensive experimental program, a setting of maximum allowable displacements would be a possible design method. These could be derived by the stress analysis methods mentioned above. But even an analysis such as this is complicated and needs theoretical development work as well as experiments.

For tubular intersections of small pipes with large pipes, the normal force acting through the small pipe could be represented by a concentrated radial load. An analysis method to calculate stresses and deflection in a cylindrical shell subjected to concentrated radial loads is 
given by Steidel and Galasso. ${ }^{61}$ As the other analysis methods mentioned before, this analysis method is only applicable in the elastic range. Analysis methods for inelastic and creep buckling are not available and have yet to be developed.

\subsection{ANALYSIS METHODS FOR LOCAL PADS FOR HANGERS, SUPPORTS, ETC.}

As in the case of tubular intersections, no analysis method is available to describe the effect of local pads on the buckling behavior of thin-walled tubes.

The recommended development work is described in Section 5.

The stress distribution in the vicinity of pads for axial loading was determined experimentally by Benicek in Reference 62. A theoretical solution to this problem performed by Mescall ${ }^{63}$ is not available to the writer at the present time.

As in the case of tubular connections, a setting of maximum allowable displacements would be a possible design method for local radial loads. A basis for this is provided by Bijlaard in his extensive work on stresses and deflections due to local loads on cylindrical shells (References 115, 116). This work was supplemented by K. R. Wichman et al. ${ }^{117}$ 


\section{REQUIRED DEVELOPMENT WORK}

The purpose of this section is to indicate the required development work based on the present state-of-the-art of instability analysis methods with emphasis on the special requirements of a piping system for liquid metals.

The development areas are identified and a possible development schedule is outlined. After solving these indicated problems it should be possible to derive analysis techniques with acceptance criteria which provide a realistic margin of safety that will not be used up by unidentified effects.

The environmental factors for a piping system in a liquid metal cooled fast reactor include:

1. High temperature differences and transients

2. Liquid metal

3. Radiation.

It is clear that for any development work the operational conditions must be known as well as possible. The environmental factors also imply a demand for time-dependent material characteristics, such as isochronous stress-strain behavior and strain-time characteristics. Since an instability analysis is very sensitive to initial imperfections, full-scale components of the piping system should be used for the experimental part of the development work. To illustrate this, the following tolerances are taken from ASTM-A 409 for large-diameter pipe:

- $-12.5 \%$ for wall thickness

- $\pm 0.40 \%$ for outside diameter 
- $1.5 \% \times$ nominal oD for out-of -roundness

- $3 / 16$-in. in $10 \mathrm{ft}$ for alignment.

Thus, permissible out-of-roundness may be as great as the wall thickness or even greater.

\section{DENTIFIED DEVELOPMENT AREAS}

The required development work is divided into three sections:

1. Experimental and analytical development for analysis methods;

2. Development of an adequate design of the piping system to avoid undesired loading conditions;

3. Development work to prepare time-dependent characteristics of the material properties and to determine the change in the pipe dimensions due to corrosion.

The following chart shows the different development areas that have been identified. The continuation of the flow chart gives some alternate ways of solution and closes with the conclusion which might result from such development work.

In addition to these principal investigations, the development work should define the effects of the nonuniformity of the temperature, the residual stresses, and the dynamic loads. If necessary, the effect of these conditions on the buckling loads should be investigated in experiments to derive correction factors for the analysis methods. 


\section{FLOW CHART FOR REQUIRED DEVELOPMENT WORK}

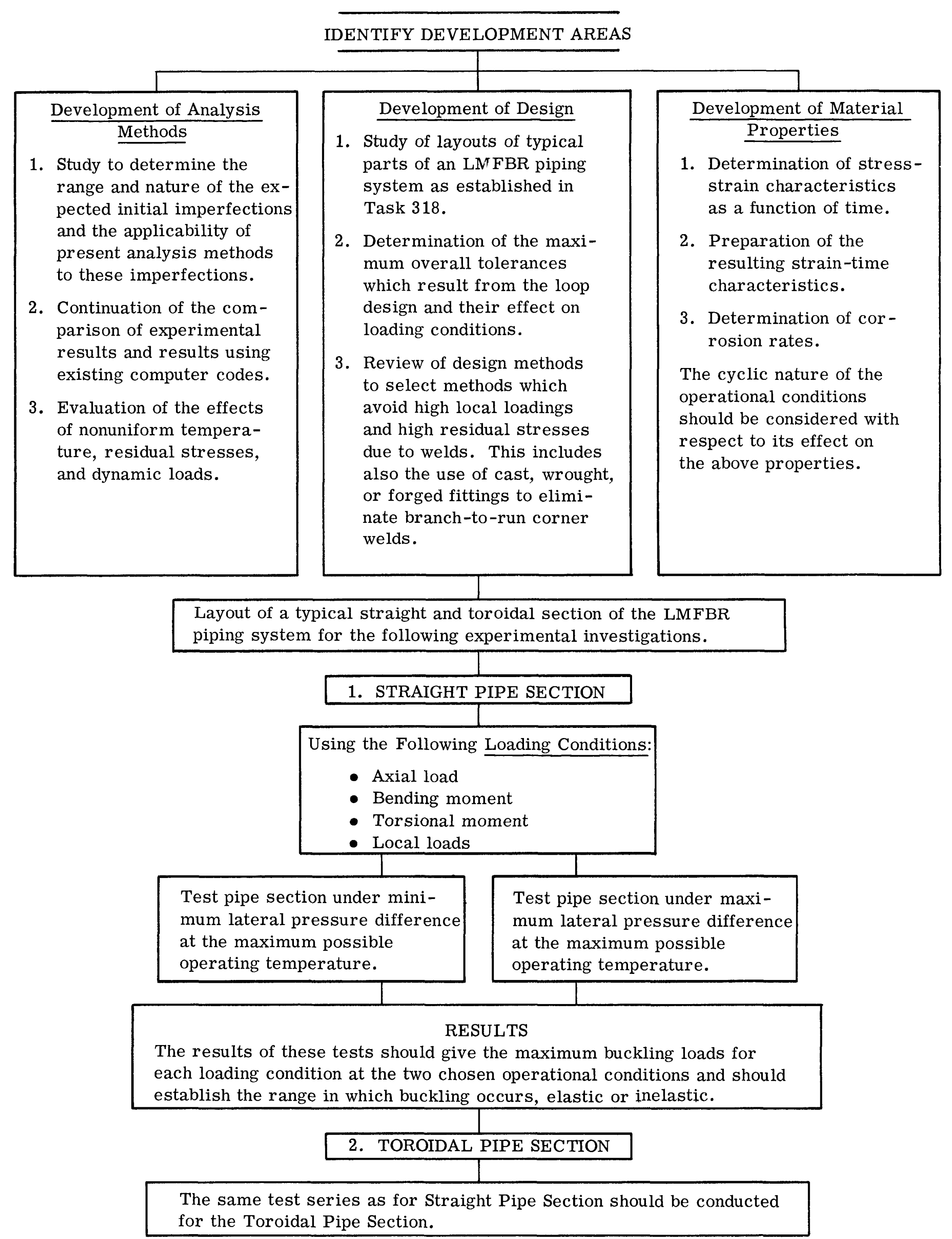




\section{COMPUTER PROGRAMS}

The descriptions of computer programs listed in this section have been obtained primarily from a survey of the literature, including such sources as reports and descriptive literature of COSMIC (University of Georgia), International Aerospace Abstracts, Franklin Institute Research Laboratory, Argonne Code Center, IBM Service Bureau, CDC COOP Library, and United Nuclear Corporation. It includes only programs which are specifically developed for buckling problems. If programs for linear or nonlinear stress analysis of thin shells are useful for establishing the design procedures, they will be evaluated in Task 790, Establish Instability Analysis Procedures. The survey work is continuing and more descriptive information has been requested.

\subsection{CODES FOR ELASTIC BUCKLING}

Elastic Buckling of Shells of Revolution with Various Wall Construc tions, BOSOR (Lockheed Aircraft Corporation) ${ }^{64-68}$

The program is written in FORTRAN-IV for the IBM-7094.

A description including a complete listing of this computer program is given by Bushnell et al. ${ }^{66}$ The program can calculate axisymmetrical collapse loads as well as bifurcation buckling loads, the latter with either a membrane solution or an accurate nonlinear solution for the prebuckling displacements. The program is easy to use but still general with respect to (1) geometry of meridian, (2) type of wall construction, (3) type of boundary conditions, and (4) type of loading. These objectives have been achieved through the provision of program branches for special cases with minimum input, in addition to a branch for the most general case. 
The general branch for the shell wall stiffness data calls for input in the form of coefficients of the constitutive equations. The following special branches calling for simpler input data are provided for: (1) shells with circumferential and meridional stiffening, (2) shells with skew stiffeners, (3) fiber-reinforced (layered) shells, (4) layered shells (isotropic or othotropic), (5) Corrugated ring-stiffened shells, and (6) shells with one corrugated and one smooth skin (with rings). The stiffness coefficients must be constant along the meridian.

The most general form of the boundary conditions for the prebuckling analysis is a set of four nonhomogeneous equations containing 20 coefficients. For the stability analysis, the homogeneous boundary conditions consist of eight equations with 64 coefficients. The general branch of the computer program calls for all these coefficients as input. Other branches are provided, however, in which coefficients of the boundary conditions are determined internally. With force or dis placement boundary conditions, only control integers are required as input. In cases with support by elastic edge rings, or support by an elastic medium, the properties of the ring or the elastic constants of the supporting medium are the input variables. The shell can be open or closed at the apex.

The following types of axially symmetric loading conditions are considered: (1) uniform normal pressure, (2) axial line loads at ends of shell, and (3) combination of uniform normal pressure and axial line load (which vary proportionally as the load is increased). The axial load need not be applied at the neutral surface of the shell. The coefficients of the constitutive equations and more details on the boundary conditions are given by Bushnell et al. ${ }^{65}$

As formulated in the computer program, the analysis has two parts. In the first part, the two equations governing the prebuckling state of the shell are solved. These are nonlinear, nonhomogeneous, second-order, ordinary differential equations. They were originally derived by Reissner. The Newton-Raphson procedure is used to solve the set of nonlinear algebraic equations which result from a finite-difference analog of the differential equations. The solution of these equations yields the quantities which appear as known variable coefficients in the equations governing the uniqueness of the equilibrium state. 
In the second part of the analysis. the stability equations (Donnelltype formulation) are solved. These equations are linear, homogeneous, fourth-order. partial differential equations. Dependence on the circumferential coordinate can be eliminated as the dependent variables are harmonic. The resulting ordinary differential equations are solved by the method of finite differences. The stability analysis is formulated as an eigenvalue problem with the lowest eigenvalue of the stability equations corresponding to the critical load. The prebuckling and stability equations are given by Bushnell et al. ${ }^{65}$

The comparison between calculated buckling loads and experimental buckling loads given in Reference 64 shows the predicted buckling loads higher in some cases than that determined by experiment. A more extensive check of the program against test results should be made before the program can be recommended as a design tool.

Static Nonlinear Analysis of Shells of Revolution Subjected to Arbitrary Loading Using the Matrix Displacement Method (Texas A \& M University) 6!.

The program is written in FORTRAN-IV for the IBM-7094.

The program has been requested by UNC and detailed information is not available at the present time. A brief description of the analysis method is given below.

The shell of revolution is idealized by a sequence of curved elements. The maximum number of elements is 50 . The following as sumptions are made:

1. Novozhilov's nonlinear thin shell theory applies

2. The linear strains are small compared with the rotations

3. The linear strains and rotations may be approximated over the meridional length of the element as their values at the middle of the element.

The buckling load is estimated by using a combined load-incre- ment/iteration method of solution. The solution converges rapidly for loads below the buckling load, but converges slowly for loads near the buckling load, and diverges for loads above the buckling load. The solu - 
tion convergence or divergence also is affected by the choice of the load increment.

The numerical accuracy of the results is a function of the input parameters, therefore considerable judgment must be used in the interpretation of the results.

Computer Analysis of Axisymmetric Buckling of Ring -Stiffened Orthotropic Shells of Revolution (Philco Corporation) ${ }^{71,72}$

Detailed information about the program has been requested. The following abstract was taken from the International Aerospace Abstracts.

"A generalization of Stodola's iteration method for beams is developed for the calculation of buckling modes of axisymmetric shell structures. The equations governing small perturbations about an axisymmetric torsionless equilibrium state are derived from small strain, moderate rotation Novozhilov shell and ring theory. These equations are recast into a selfadjoint system of eigenvalue equations with the load factor $\lambda$, to which the load distribution is assumed proportional, as parameter. Because of the nonlinear dependence of the prebuckling state on $\lambda$, in general it is necessary to approach the critical eigenvalue (for a given circumferential wave number) by the solution of a sequence of modified eigenvalue problems, the first of which corresponds to the linearized prebuckling state. $\mathrm{Nu}$ merical results are presented for (1) a ring-stiffened simply supported cylindrical shell previously studied as an equivalent or thotropic shell, (2) a prolate spheroidal shell previously studied by the Rayleigh-Ritz method, and (3) a ring-stiffened prolate spheroidal shell for which no previous theoretical results exist. The first example illustrates the effect of ring eccentricity, indicating that internal rings can be significantly more effective in resisting external hydrostatic pressure than external rings. In all cases excellent agreement with previous experimental results was obtained." 


\subsection{CODES FOR INELASTIC BUCKLING}

COLLAPSE - Instantaneous Buckling of Circular Cylinders with Initial Out-of-Roundness under External Pressure (United Nuclear Corporation - Company Proprietary) ${ }^{1,27,73}$

The program is written in FORTRAN-63 for the CDC-1604-A.

The analysis method is based on the theory of Corum. ${ }^{4}$ and is similar to a one-dimensional analysis for the inelastic buckling of excentrically loaded columns with initial imperfections given in Timoshenko. ${ }^{27}$ The initial out-of-roundness is assumed to be independent of axial coordinates and of quasi-elliptical form. End effects are neglected.

The central idea of the theory is that buckling occurs when the equilibrium between the shape-changing effect of the applied pressure and the shape-restoring effect of the resulting strains becomes an unstable one. The "applied bending moments" which measure the shapechanging effects of the uniform external lateral pressure vanish for a circular tube and are proportional to the ovality parameter which measures the amount by which the tube is out of round. The restoring moments are proportional to the internal stresses that develop with a change in ovality due to strain. At equilibrium, the restoring moments balance the applied moments. When a further increase of strain ovality results in a restoring moment increment that is less than the applied moment increment, it becomes impossible to achieve a new equilibrium for any slight increase of strain or pressure, and the tube buckles.

This point is obtained by iteration. The basic equations are given in Reference 73.

The program includes an iterative scheme which is used to calculate the buckling pressure as a function of initial ovality. A comparison between experimental buckling pressure and buckling pressures calculated with the program is shown in Table 3.2 of Section 3.5. The agreement is fairly good with a conservatism of approximately 10 to $20 \%$.

Limit Analysis of Shells of Revolution by Linear Programming (Cornell University, Ithaca, N. Y.) ${ }^{74}$

Detailed information about the program has been requested. The 
following abstract was taken from the International Aerospace Abstracts.

"A method of plastic limit analysis involving the use of linear programming is outlined, which makes it possible to determine veloc ity fields and corresponding upper bounds to the collapse load of a broad class of shells of revolution. The shell may be subjected to a wide range of loading and boundary conditions. Tresca's yield condition and flow rule are assumed to govern the behavior of the rigid, perfectly plastic shell material. Excellent agreement is obtained with currently available complete solutions for built-in spherical sandwich shells subjected to uniform pressure."

\subsection{CODES FOR CREEP BUCKLING}

Creep Buckling of Cylindrical Tubes under External Pressure, CRE-BUCK (United Nuclear Corporation - Company Proprietary) (10,73,75,76 $^{2}$

The program is written in FORTRAN-63 for the CDC-1604-A.

Starting with initial elastic conditions the program calculates the accumulated change in creep strain and total strain, and the resulting deflection. A numerical method is used in which the time is divided up into a large number of small time intervals. These time intervals are taken small enough such that the stress can be considered to be constant during the time interval and to increase as a step function at the end of the time interval. By considering the stresses constant during a particular interval, the change in creep strain and total strain can be determined. Once the changes in total strains have been determined, the changes in elastic strains can be evaluated by subtracting the changes in creep strain from the changes in total strains. Next, the changes in stress can be calculated by use of the elastic stress-strain relations. The change in the radial deflection is then determined by integrating the change of the average tangential strain over one-quarter of the circumference. The newly determined stresses are held constant during the next time interval and the calculation as mentioned above is repeated. This cyclic process continues until the maximum deflection (which is an input number) is reached. Considering the maximum deflection equal to the deflection at which instantaneous buckling would occur, the program calculates the critical lifetime. 
The program offers a choice between Tresca and ron Mises flow rule and between strain-hardening and time-hardening creep laws. A comparison between experimental data and predicted data was made and is shown in Fig. 6.1. As can be seen from Fig. 6.1. both the ron Mises flow rule and the Tresca flow rule appear to give conservative estimates of the deformation as a function of time. The test data were taken from Reference 50, representing a creep test rum on an Inconel-625 tube at $1256^{\circ} \mathrm{F}$ and under an external pressure of $2702 \mathrm{ps}$. The specmen tested had a mean radius of $0.1314 \mathrm{in}$. and a wall thickness of $0.0162 \mathrm{in}$. The pressure deformation was added to the measured experimental data to allow direct comparison with the computer program.

References 20 and 22 include descriptions of computer programs which predict the creep buckling of axially compressed cylinders with and without internal pressure. Information on the availability of these programs has been requested. 


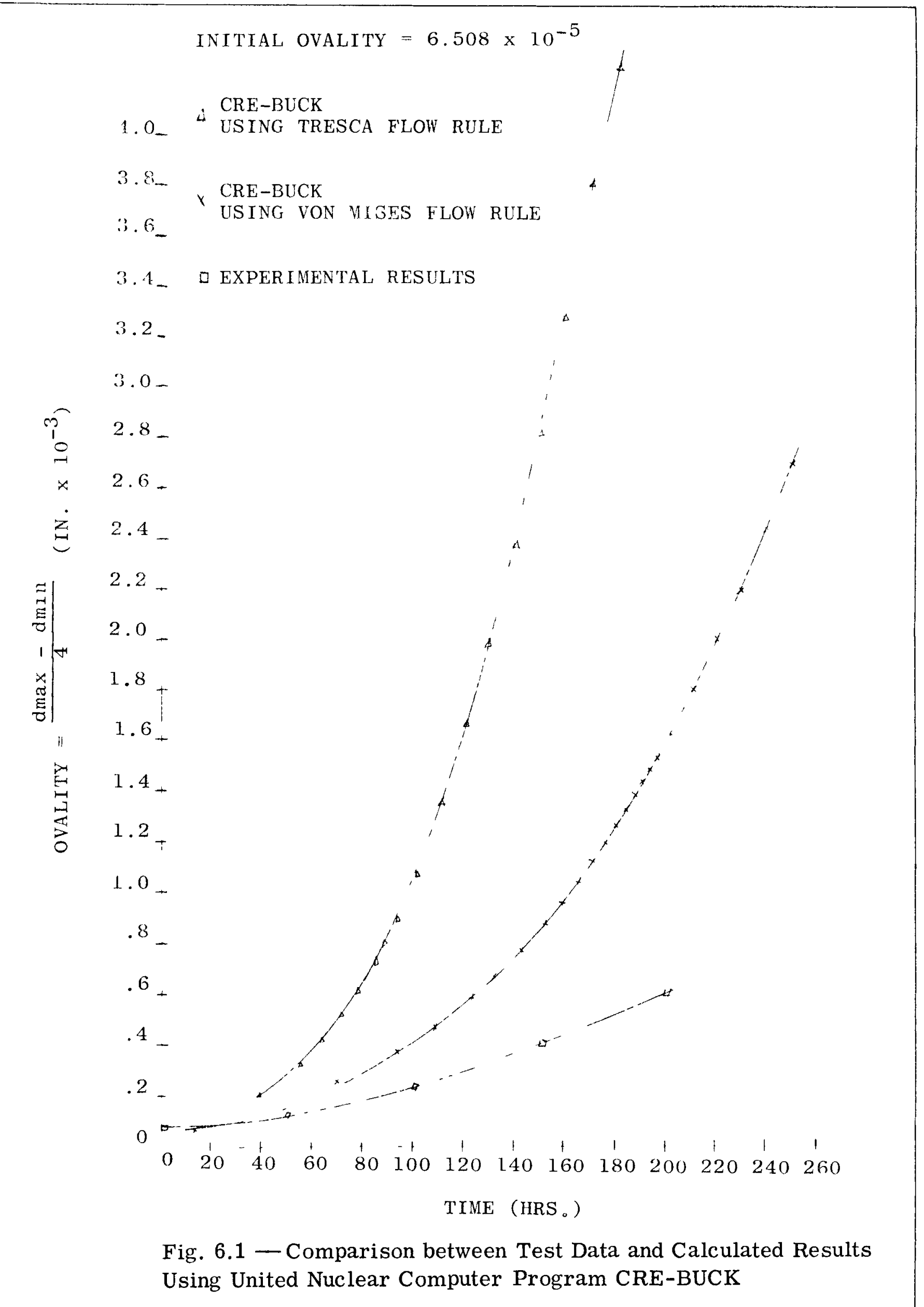

Fig. 6.1 - Comparison between Test Data and Calculated Results Using United Nuclear Computer Program CRE-BUCK 


\section{RECOMMENDATIONS FOR INSTABILITY ANALYSIS PROCEDURES}

A review has been made of the present state-of-the-art in theoretical and experimental determination of critical buckling loads for various expected loading conditions. The consistency of the agreement between existing analysis methods and experiments is the main factor in choosing the recommended analysis methods for design purposes. Where experimental data is not available the presently known theoretical methods will be recommended as the best available procedures to date. The following recommendations are based on the assumption that the scope of the initial phase of the design guide for LMFBR piping does not include the development of major computer programs for analysis methods. Any change in the recommendations which might result from new information or development work will be taken into account in Task 418, "Establish Instability Analysis Procedures."

\section{1 INSTABILITY IN THE ELASTIC RANGE}

For instability in the elastic range, statistical analysis methods are recommended as given in References 13 and 41 . This would require that the existing range of experimental results be expanded by an experimental program in the range of interest and that the experimental data obtained be compared with the analytical solutions to determine statistical probabilities for the deviation between the theoretical and experimental values. This procedure was used with considerable success for the buckling of cylindrical shells under combined internal pressure and axial loading in Reference 13 and for combined internal pressure and bending in Reference 41.

For instability under certain loading conditions, to which this method is not applicable because of insufficient experimental investigation, approximate analytical solutions are recommended, combined with analytical or experimental development work. 
With regard to the computer programs, insufficient information has been obtained to permit a final conclusion as to their advantages or disadvantages, and a detailed check of the programs against experimental results is recommended.

Very long cylinders must be checked for buckling as Euler columns.

\subsubsection{Axial Compression}

Use the theoretical solution, based on Equation 3.1, given in Section 3.1.1, and the statistical analysis methods of Reference 13. This procedure provides that the available experimental data be compared with the analytical solutions to determine statistical probabilities for the deviation between the theoretical and experimental values.

\subsubsection{Axial Compression Plus Internal Pressure}

The same method as for axial compression is recommended with an additional correction factor to describe the increase in the critical buckling load due to the internal pressure.

\subsubsection{Axial Compression Plus External Pressure}

The theoretical solution in Reference 27 is recommended for further study as indicated in Section 3.1.3. Further analytical and experimental information is required to substantiate any recommendation regarding the buckling behavior under combinations of axial compression and external pressure.

\subsubsection{Torsion}

The theoretical solution given by Timoshenko ${ }^{27}$, and shown on Page 3-16, should be used for long cylinders, while Equations 3. 7 and 3. 8, derived by Donnell are recommended for short and intermediate length cylinders. The theory predicts critical stresses which are somewhat higher than actual values, however, the differences over a wide range are a fairly consistent ratio, and can be accounted for in a factor for design.

\subsubsection{Torsion Plus External or Internal Pressure}

The interaction curves of Suer and Harris ${ }^{37}$ and Eckstrom ${ }^{33}$ as described in Sections 3.22 and 3.23 and shown in Figures 3.14, 3.15, and 3.16, are recommended. The applicability of this method to the range of interest should be checked. 


\subsubsection{Bending}

For the buckling behavior of a shell under a bending moment, the same method is recommended as for the case of axial compression. The theoretical solution of Reference 41 will be used corrected by the buckling coefficient established by statistical evaluation of the experimental results.

\subsubsection{Bending Plus Internal Pressure}

A thoretical analysis has been developed and experimental data has been presented by Suer et $\mathrm{al}^{41}$. It is recommended that correction factors be established based on a statistical analysis as indicated in Section 7.1.1 for axial loads.

\subsubsection{Lateral External Pressure}

The analysis method developed by Donnell in Reference 46 is recommended. This method provides correction factors for initial imperfections. It also is recommended that comparisons be made with experimental data on specimens with initial imperfections (out-of-roundness) as well as data on near perfect specimens such as shown in Figure 25.

\section{2 INSTABILITY IN THE INELASTIC RANGE}

The analysis methods given by Corum ${ }^{4}$ for external pressure, by Ades ${ }^{5}$ for bending and by Battermann ${ }^{6}$ for axial compression are recommended. The results, however, are sensitive to the edge conditions (simply supported or clamped) and to the initial imperfections, and considerable judgment must be used in assuming the initial conditions and interpreting the results. A comparison between the theory and experiments for radius-to-wall thickness ratios in the range of interest is recommended.

\subsubsection{Axial Compression}

A theoretical solution based on Reference 6 is recommended, using either deformation or incremental theory. A study of and comparison of these two theories will be made in Task 211. The development of a correction factor to describe the effect of internal or external pressure is recommended.

\subsubsection{Torsion}

Plasticity reduction factors of Gerard ${ }^{16}$, Equations 3.9 and 3.10, are recommended, and a check of the theoretical values against experimental data as recommended in Section 5. (This might be done as a part of Task 418.) 


\subsubsection{Bending}

The theory of Ades ${ }^{5}$ is recommended if the related existing computer program is available. Otherwise additional development work is required to develop a program.

\section{2.4 External Pressure}

The theory of Corum ${ }^{4}$ and the related computer program COLLAPSE* developed by United Nuclear Corporation are recommended. The comparison between predicted and actual critical collapse pressures should be expanded to the range of interest of the $\mathrm{R} / \mathrm{H}$ ratios.

\section{3 INSTABILITY DUE TO CREEP}

The analysis methods by Hoff ${ }^{19}$ and Samuelson ${ }^{21}$ and the United Nuclear Program CRE-BUCK ${ }^{76,75 *}$ are recommended for initial use and further study. The applicability of this method to the creep behavior under cyclic operational conditions has yet to be proved. An important factor in the ability of these codes to predict buckling due to creep is the reliability of the time-dependent stress-strain characteristics and the creep data. Therefore, it is recommended that the necessary data be obtained as a part of Tasks 228 and 315.

\subsubsection{Axial Compression}

The method of Diamant ${ }^{20}$ or Samuelson ${ }^{21,22}$ are recommended if the related existing computer programs can be obtained. Otherwise, the simplified method of Hoff ${ }^{19}$ should be checked against experimental data.

\subsubsection{Torsion}

Methods for calculating the creep-buckling behavior of tubes in torsion require further development. A method of calculating the critical shear strain at which torsional buckling occurs was developed by Finnie in Reference 36. This should be included in the development of an analysis method to calculate the time-dependent deformation.

\subsubsection{Bending}

The theoretical solution of this problem, worked out by Samuelson and indicated in Reference 21, is not available at the present time, but has been requested. If this work is not available, an analysis method will have to be developed.

*Programs CRE-BUCK and COLLAPSE are presently considered as United Nuclear Proprietary. The above recommendations are contingent upon these programs being placed in the public domain. 


\subsubsection{External Pressure}

The computer program CRE-BUCK, developed by United Nuclear Corporation, is recommended for initial use and further study. The applicability of this method to the creep behavior in the range of interest has yet to be proved.

\section{4 RECOMMENDATIONS FOR DETERMINING THE LOAD CARRYING CAPACITY OF PIPING COMPONENTS SUCH AS ELBOWS, RETURNS, LATERALS, TEE'S, PADS FOR HANGERS, SUPPORTS, ETC.}

Analysis methods for elastic, inelastic, and creep buckling are not available and further study and development in this area are required. The review of design methods to avoid local loadings and provide limitations on deflections and stress concentrations is recommended.

\subsection{Discussion of Applicable Methods}

The review of design methods recommended in Section 5 should result in a selection of design procedures which avoid high local loads and reduce to a minimum the possibility that instability will occur in a component. Because of the mathematical complexity of an instability analysis of such a component, limitation of the deflections and stress concentrations is recommended. For elbows and returns the deflection and stress concentration are determined by the flexibility analysis. For laterals and tee's of equal pipe size the analysis method of Greste and Clough, Reference 60 , is recommended. For tubular connections of pipes of different sizes, and local attachments, Bijlaard's analysis method, References 115, 116, 117 , is recommended.

A possible approximate analysis method to determine the critical buckling loads of components is to replace the critical section of the component with a curved panel or rectangular plate and perform the analysis on these geometries. This method is described in Section 4.1.

The recommended experimental development work, described in Sections 4 and 5 , is required to provide information to verify the analytical methods. 


\section{BIBLIOGRAPHY}

1. Haskell, Donald F.: The Influence of Residual Stress on Yield and Elastic Buckling of Tubes under External Lateral Pressure, ANS Transactions, 11:2 (1968).

2. Ogibalov, P. M.: Dynamics and Strength of Shells, NASA-TT-F $284(1966)$.

3. Anderson, D. L. and Lindberg, H. E.: Dynamic Pulse Buckling of Cylindrical Shells under Transient Lateral Pressures, AIAA Journal, 6:4 (1968).

4. Corum, J. M.: An Investigation of the Instantaneous and Creep Buckling of Initially Out-of-Round Tubes Subjected to External Pressure, ORNL-3299 and ORNL-3555.

5. Ades, Clifford S.: Bending Strength of Tubing in the Plastic Range, J. of the Aeronautical Sci. (Aug. 1957).

6. Battermann, S. C.: Free-Edge Plastic Buckling of Axially Compressed Cylindrical Shells, J. of Appl. Mech. (Mar. 1968).

7. Stein, Manuel: Some Recent Advances in the Investigation of Shell Buckling, AIAA Journal, 6:2 (Dec. 1968).

8. Schwarzwälder, R. and Wolf, O.: Theoretical and Experimental Studies on the Stresses and Strains in Claddings of Annular BoilingSuperheat Fuel Elements, Nuclear Structural Eng., 2 (1965).

9. Karman, T. v. and Tsien, H. S.: The Buckling of Thin Cylindrical Shells under Axial Compression, J. of the Aeronautical Sci., 8:8 (1941). 
10. Kempner, J.: Postbuckling Behavior of Axially Compressed Circular Cylindrical Shells, J. of the Aeronautical Sci., 21:5 (1954).

11. Almroth, B.: Postbuckling Behavior of Orthotropic Cylinders under Axial Compression, AIAA Journal, 2:10 (1964).

12. Donnell, L. H. and Wan, C. C.: Effect of Imperfections on Buckling of Thin Cylinders and Columns under Axial Compression, J. Appl. Mech., 17:1 (1950).

13. Harris, L. A. et al.: The Stability of Thin-Walled Unstiffened Circular Cylinders under Axial Compression Including the Effects of Internal Pressure, J. of the Aeronautical Sci. (Aug. 1957).

14. Bolotin, V. V.: Application of Methods of the Theory of Probability in the Theory of Plates and Shells, also Vorovich, I.I.: Certain Problems of the Use of Statistical Methods in the Theory of Stability of Plates and Shells, NASA-TT-F-341 (1966).

15. Bijlaard, P. P.: Theory and Tests on the Plastic Stability of Plates and Shells, J. of the Aeronautical Sci. (Sept. 1949).

16. Gerard, G.: Plastic Stability Theory of Thin Shells, J. of the Aeronautical Sci. (Apr. 1957).

17. Gerard, G.: On the Role of Initial Imperfections in Plastic Buckling of Cylinders under Axial Compression, J. of the Aeronautical Sci. (June 1962).

18. Battermann, S. C.: Plastic Buckling of Axially Compressed Cylindrical Shells, AIAA Journal, 3:2 (Feb. 1965).

19. Hoff, N. J.: Axially Symmetric Creep Buckling of Circular Cylindrical Shells in Axial Compression, J. of Appl. Mech. (Sept. 1968).

20. Diamant, E. S.: Axisymmetric Creep in Cylindrical Shells, AIAA Journal (Oct. 1967).

21. Samuelson, L. A.: Creep Buckling of an Elastic-Plastic Cylindrical Shell, AIAA Journal (Dec. 1968).

22. Samuelson, L. A.: Creep Buckling of a Circular Cylindrical Shell, AIAA Journal (Jan. 1969).

23. Fluegge, W.: Die Stabilitaet der Kreiszylinderschale, Ing.-Archiv. Bd III Heft 5 (Dec. 1932). 
24. Lo, H., Crate, H., and Schwarz, E. B.: Buckling of Thin-Walled Cylinder under Axial Compression and Internal Pressure, NACA-TN-2021 (Jan. 1950).

25. Weingarten, V. I. et al.: Elastic Stability of Thin-Walled Cylindrical and Conical Shells Under Combined Internal Pressure and Axial Compression, AIAA Journal (June 1965).

26. Hutchinson, J.: Axial Buckling of Pressurized Imperfect Cylindrical Shells, AIAA Journal (Aug. 1965).

27. Timoshenko, S. P. and Gere, J. M.: "Theory of Elastic Stability," McGraw-Hill Book Company, 1961.

28. Jones, B. H.: Assessing Instability of Thin-Walled Tubes under Biaxial Stresses in the Plastic Range, Experimental Mechanics (Jan. 1968).

29. Bert, C. W. et al.: Effect of Variation in Poisson's Ratio on Plastic Tensile Instability, J. of Basic Eng. (Mar. 1967).

30. Bert, C. W. and Reese, C. D.: Ductile Creep Rupture of Shells with Strain Hardening and Time-Dependent Loading, J. of Basic Eng. (June 1968).

31. Schwerin, E.: Buckling of Shells under Torsion, Zeitschrift angew. Math. u. Mech., Vol. 5 (1925).

32. Yoshimura, Y., and Niisawa, J.: Lower Buckling Stress of Circular Cylindrical Shells Subjected to Torsion, J. of the Aeronautical Sci。(Mar. 1957).

33. Ekstrom, R. E.: Buckling of Cylindrical Shells Under Combined Torsion and Hydrostatic Pressure, Experimental Mech. (Aug. 1963).

34. Budiansky, B.: Post-Buckling Behavior of Cylinders in Torsion, Report SM-17, Harvard University (Aug. 1967).

35. Lee, L. H. N., and Ades, C. S.: Plastic Torsional Buckling Strength of Cylinders Including the Effects of Imperfections, J. of the Aeronautical Sci. (Apr. 1957).

36. Finnie, I.: Creep Buckling of Tubes in Torsion, J. of the Aeronautical Sci. (Jan. 1958). 
37. Suer, H. S. and Harris, L. A.: The Stability of Thin-Walled Cylinders under Combined Torsion and External Lateral or Hydrostatic Pressure. J. of Appl. Mech. (Mar. 1959).

38. Crate, H. et al.: The Effect of Internal Pressure on the Buckling Stress of Thin-Walled Circular Cylinders under Torsion. NACA ARR No. L4E27 (May 1944).

39. Hopkins, H. G. and Brown, E. H.: The Effect of Internal Pressure on the Initial Buckling of Thin-Walled Circular Cylinders under Torsion, British Aeronautical Research Council, R\&M No. 2423 (Jan. 1950).

40. Seide, P. and Weingarten, V. I.: On the Buckling of Circular Cylindrical Shells under Pure Bending, J. of Appl. Mech. (Mar. 1961).

41. Suer, H. S. et al.: The Bending Stability of Thin-Walled Unstiffened Circular Cylinders Including the Effect of Internal Pressure, J. of the Aeronautical Sci. (May 1958).

42. Samuelson, L. A.: Experimental Investigation of Creep Buckling of Circular Cylindrical Shells under Axial Compression and Bending, J. of Eng. for Industry (Nov. 1968).

43. Weingarten, V. I.: Effects of Internal Pressure on the Buckling of Circular-Cylindrical Shells under Bending, J. of the Aerospace Sci. (July 1962).

44. Felgar, R. P.: Plastic Analysis of the Instability of Pressure Vessels Subjected to Internal Pressure and Axial Load, J. of Basic Eng. (June 1962).

45. Batdorf, S. B.: A Simplified Method of Elastic Stability Analysis for Thin Cylindrical Shells, NACA Report No. 874 (1947).

46. Donnell, L. H.: Effect of Imperfections on Buckling of Thin Cylinders under External Pressure, J. of Appl. Mech., 23:4 (1956).

47. Sanders, J. L. et al.: A Variational Theorem for Creep with Application to Plates and Columns, NCAA Report (1958).

48. Hoff, N. J. et al.: A Study of Creep Collapse of a Long Cylinder under Uniform External Pressure, J. of the Aerospace Sci., 26 (1959). 
49. Ellington, J. P.: Creep Collapse of Tubes under External Pressure, DEG Report 162 (R) U.K.A.E.A.

50. Glueckler, E. et al.: Creep Buckling of Fuel Element Claddings, Nuclear Eng. and Des., 7 (1968).

51. Vissat, P. L. and Del Buono, A. J.: In-Plane Bending Properties of Welding Elbows, Transactions of the ASME, 77 (1955).

52. Karman, T. v.: Über die Formänderung dünnwandiger Rohre, insbesonders federnder Ausgleichsrohre, Zeitschrift des V.D.I., Vol. 55 (1911).

53. Beskin, L.: Bending of Thin Curved Tubes, J. of Appl. Mech., 55 (1945).

54. Symonds, P. S. and Pardue, T. E.: Characteristics of Short Radius Tube Bends, Naval Research Laboratory Report No. 0-2761, No. 0-2963 (1946).

55. Gross, N. and Ford, H.: The Flexibility of Short Radius Pipe Bends, The Inst. of Mech. Eng., London (Dec. 1952).

56. Sobel, L. H. and Fluegge, W.: Stability of Toroidal Shells under External Pressure, AIAA Journal (Mar. 1967).

57. Levy, S.: Shear and Bending of the Walls of Short Cylindrical Shells, Transactions of the ASME, Paper No. 64 - WA/MD-9.

58. Beale, L. A. and Toprac, A. A.: Analysis of In-Plane T, Y, and K Welded Tubular Connections, Welding Research Council 125 (Oct. 1967).

59. Hansberry, J. W. and Jones, N.: A Theoretical Study of the Elastic Behavior of Two Normally Intersecting Cylindrical Shells, J. of Eng. for Industry, Paper No. 68-WA/PVP-1.

60. Greste, O. and Clough, R. W.: Finite Element Analysis of Tubular Joints: A Report on a Feasibility Study, Univer sity of California, Structures and Materials Research, Dept. of Civil Eng., Report No. 67-7.

61. Steidel, R. F. and Galasso, M.: Stresses and Deflection in a Cylindrical Shell Subjected to Concentrated Radial Loads, ASME Publication Paper No. 61-WA-2. 
62. Benicek, M.: Experimental Study of Thin Cylindrical Shells under Local Axial Loadings, Experimental Mech. (Dec. 1967).

63. Mescall, J. F.: Thin Cylindrical Shells under Local Axial Loadings, U. S. Army Res. Agency Tech. Report, AMRA TR 64-39 (Dec. 1964).

64. Bushnell, D. et al.: Buckling of Shells of Revolution With Various Wall Constructions, Users Manual Vol. 1, NASA CR-1049 (May 1968).

65. Bushnell, D. et al.: Buckling of Shells of Revolution With Various Wall Constructions, Users Manual Vol. 2, NASA CR-1050 (May 1968).

66. Bushnell, D. et al.: Buckling of Shells of Revolution With Various Wall Constructions, Users Manual Vol. 3, NASA CR-1051 (May 1968).

67. Bushnell, D.: Nonlinear Axisymmetric Behavior of Shells of Revolution, AIAA Journal (Mar. 1967).

68. Almroth, B. O. et al.: Computer Analysis of Various Shells of Revolution, AIAA Journal (Oct. 1968).

69. Stricklin, J. A. and Haisler, W. E.: Nonlinear Analysis of Shells of Revolution by the Matrix Displacement Method, AIAA Journal (Dec. 1968).

70. Stricklin, J. A. et al.: Nonlinear Analysis of Shells of Revolution by the Matrix Displacement Method, CONF-680101--2

71. Cohen, G. A.: Computer Analysis of Asymmetric Buckling of Ring-Stiffened or Orthotropic Shells of Revolution, International Aerospace Abstracts, A67-18339.

72. Cohen, G. A.: Computer Analysis of Asymmetric Buckling of Ring-Stiffened Orthotropic Shells of Revolution, AIAA Journal (Jan. 1968).

73. UNC Inter-Office Memo, Phys/Math 5311 (Company Proprietary).

74. Lance, R. H. and Koopman, D. C. A.: Limit Analysis of Shells of Revolution by Linear Programming, International Aerospace Abstracts, A68-42987. 
75. UNC Preliminary Report (Company Proprietary): Creep Buckling of Tubes under External Pressure.

76. Comparison of Flow Theories in Predicting Creep Determinations, UNC MDEO-2145 (Jan. 6, 1968).

77. Poesch, W. L.: A Remark on the Optimum Design of Round Tubing, J. of the Aeronautical Sci. (Mar. 1958).

78. Hoff, N. J. and Rehfield, L. W.: Buckling of Axially Compressed Circular Cylindrical Shells at Stresses Smaller Than the Classical Critical Value, J. of Appl. Mech. Paper No. 65-APM-21.

79. Hoff, N. J.: Low Buckling Stresses of Axially Compressed Circular Cylindrical Shells of Finite Length, J. of Appl. Mech. Paper No. 65-APMW-4.

80. Serbin, H.: Conceptual Methods in the Theory of Thin Elastic Shells, J. of the Aeronautical Sci. (Oct. 1962).

81. Jones, R. M.: Buckling of Circular Cylindrical Shells With Multiple Orthotropic Layers and Eccentric Stiffeners, AIAA Journal (Dec. 1968).

82. De Neufville, R. L.: Influence of Geometry on the Number of Buckles in Cylinders, AIAA Journal (Feb. 1965).

83. Harris, L. A. et al.: The Effect of Internal Pressure of the Buckling Stress of Thin-Walled Circular Cylinders under Combined Axial Compression and Torsion, J. of the Aeronautical Sci. Feb. 1958).

84. Ting, L. and Yuan, S. W.: On Radial Deflection of a Cylinder of Finite Length With Various End Conditions, J. of the Aeronautical Sci. (Apr. 1958).

85. Seide, P.: On the Bending of Circular Cylindrical Shells by Equal and Equally Spaced End Radial Shear Forces and Moments, J. of Appl. Mech. (Mar. 1961).

86. Fine, A. D.: A Stress-Strain Approximation in Plasticity, AIAA Journal, 5:10. 
87. Nordgren, R. P. and Murphey, C. E.: Elastic Stability of Circular Tubes of Circumferentially Variable Thickness under External Pressure, J. of Eng. for Industry (Nov. 1968).

88. Lepik, $\ddot{\mathrm{U}}$.: Large Deflections of Rigid-Plastic Cylindrical Shells under Axial Tension and External Pressure, Nuclear Eng. and Des., 4 (1966).

89. Assmann H. and Steinberg, E.: Stabilitätsuntersuchung an dünnwandigen Brennstoffhüllen, Atompraxis 13 Heft 2 (1967).

90. Holston, A., Jr.: Buckling of Inhomogeneous Anisotropic Cylindrical Shells by Bending, AIAA Journal (Oct. 1968).

91. Cheng, S. and Ho. B. P. C.: Stability of Heterogeneous Aeolotropic Cylindrical Shells under Combined Loading, AIAA Journal (Apr. 1963).

92. Hedgepeth, J. M. and Hall, D. B.: Stability of Stiffened Cylinders, AIAA Journal (Dec. 1965).

93. Ho, B. P. C. and Cheng, S.: Some Problems in Stability of Heterogeneous Aeolotropic Cylindrical Shells under Combined Loading, AIAA Journal (July 1963).

94. Ugural, A. C. and Cheng, S.: Buckling of Composite Cylindrical Shells under Pure Bending, AIAA Journal (Feb. 1968).

95. Holston, A. Jr.: Stability of Inhomogeneous Anisotropic Cylindrical Shells Containing Elastic Cores, AIAA Journal (June 1968).

96. Tasi, J.: Effect of Heterogeneity on the Stability of Composite Cylindrical Shells under Axial Compression, AIAA Journal (June 1966).

97. Mah, G. B. et al.: Buckling of Orthotropic Cylinders, AIAA Journal (Apr. 1968).

98. Mason, P. et al.: Nonlinear Numerical Analysis of Axisymmetrically Loaded Arbitrary Shells of Revolution, AIAA Journal (July 1965).

99. Hoff, N. J.: Thin Shells in Aerospace Structures, J. of Astronautics and Aeronautics (Feb. 1967). 
100. Stokey, W. F. et al.: Limit Loads for Tubes under Internal Pressure Bending Moment, Axial Force, and Torsion, Nuclear Eng. and Des., 4 (1966).

101. McKeon, J. T.: Primary Piping Flexibility Analysis for LiquidMetal-Cooled Fast Breeder Reactors, Nuclear Eng. and Des., 7 (1968).

102. Budiansky, B. and Hutchinson, J. W.: A Survey of Some Buckling Problems, AIAA Journal (Sept. 1966).

103. Ross, B. et al.: Buckling of Thin Cylindrical Shells Heated along an Axial Strip, Experimental Mech. (Aug. 1965).

104. Allentuch, A. et al.: Long Cylindrical Shell under Loads Applied to a Reinforcing Ring, AIAA Journal (Oct. 1967).

105. Almroth, B. O.: Influence of Edge Conditions on the Stability of Axially Compressed Cylindrical Shells, AIAA Journal (Jan. 1966).

106. Montague, P. and Horne, M. R.: Elastic-Plastic, Axisymmetric Analysis of a Thin-Walled Cylindrical Shell Subjected to a Radial Pressure Difference, J. of Appl. Mech. (Dec. 1968).

107. Structures Manual, Vol. 2, North American Aviation, Inc. NAA-SID-543-G11 (1964).

108. Gerard, G. and Becker, H.: Handbook of Structural Stability, Part III - Buckling of Curved Plates and Shells, NACA-TN-3783 (1957).

109. Pfennigwerth, P. L.: Stress Analysis With Applications to Pressurized Water Reactors, WAPD TM 300.

110. Goodier, J. N. and Hoff, N. J.: Structural Mechanics, Proceedings of the First Symposium on Naval Structural Mech. (Aug. 1958). Pergamon Press, 1960.

111. Collected Papers on Instability of Shell Structures, NASA TN D-1510 (1962).

112. Baker, E. H. et al.: Shell Analysis Manual, NASA CR-912. 
113. Mushtari, Kh. M. and Galimov, K. Z.: Nonlinear Theory of Thin Elastic Shells, NASA-TT-F62.

114. Flügge, W.: "Stresses in Shells," Springer Verlag, Inc., New York, 1967.

115. Bijlaard, P. P.: Additional Data on Stresses in Cylindrical Shells under Local Loading, Welding Research Council Bulletin No. 50 10-50 (May 1959).

116. Bijlaard, P. P. and Cranch, E. T.: Interpretive Commentary on the Application of Theory to Experimental Results for Stresses and Deflections Due to Local Loads on Cylindrical Shells, Welding Research Council Bulletin No. 60 1-2 (May 1960).

117. Wichman, K. R。 et al.: Local Stresses in Spherical and Cylindrical Shells Due to External Loadings, Welding Research Council Bulletin No. 107 (Aug. 1965).

118. Berman, R. M. et al.: Properties of Zircaloy-4 Tubing, WAPD-TM-585 (Dec. 1966).

119. Skankard, R. C.: Tests of the Elastic Stability of a Ring-Stiffened Cylindrical Shell, Model BR-4 $(\lambda=1.103)$ Subjected to Hydrostatic Pressure, David Taylor Model Basin, Report No. 876 (Feb. 1955). 